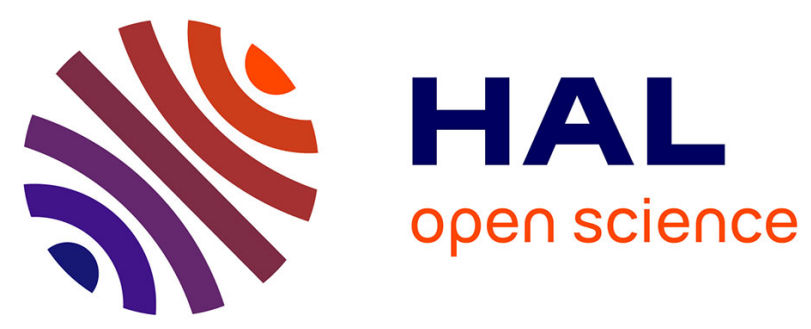

\title{
Synthesis of $\mathrm{NiF} 2$ and $\mathrm{NiF} 2 \times 4 \mathrm{H} 2 \mathrm{O}$ Nanoparticles by Microemulsion and Their Self-Assembly
}

Hameed Ullah, Nicolas Batisse, Katia Guérin, Guillaume Rogez, Pierre Bonnet

\section{To cite this version:}

Hameed Ullah, Nicolas Batisse, Katia Guérin, Guillaume Rogez, Pierre Bonnet. Synthesis of NiF 2 and NiF $2 \times 4 \mathrm{H} 2$ O Nanoparticles by Microemulsion and Their Self-Assembly. Langmuir, 2020, 36 (29), pp.8461-8475. 10.1021/acs.langmuir.0c00889 . hal-02926198

\section{HAL Id: hal-02926198 \\ https://hal.science/hal-02926198}

Submitted on 10 Nov 2020

HAL is a multi-disciplinary open access archive for the deposit and dissemination of scientific research documents, whether they are published or not. The documents may come from teaching and research institutions in France or abroad, or from public or private research centers.
L'archive ouverte pluridisciplinaire HAL, est destinée au dépôt et à la diffusion de documents scientifiques de niveau recherche, publiés ou non, émanant des établissements d'enseignement et de recherche français ou étrangers, des laboratoires publics ou privés. 


\section{Synthesis of $\mathrm{NiF}_{2}$ and $\mathrm{NiF}_{2} \cdot \mathbf{4} \mathrm{H}_{2} \mathrm{O}$ nanoparticles by microemulsion and their self-assembly}

Hameed Ullah ${ }^{* 1,2,3}$, Nicolas Batisse ${ }^{1}$, Katia Guerin ${ }^{1}$, Guillaume Rogez ${ }^{4}$ and Pierre Bonnet ${ }^{*}{ }^{1}$

${ }^{1}$ Institut de Chimie de Clermont-Ferrand, Université Clermont Auvergne, UMR 6296, BP 10448, F-63000 Clermont-Ferrand, France

${ }^{2}$ Department of Chemistry, Hazara University, Mansehra 21300, Pakistan

${ }^{3}$ Department of Chemistry, Islamia College Peshawar 25120, Pakistan

${ }^{4}$ Institut de Physique et Chimie des Matériaux de Strasbourg, University of Strasbourg, CNRS UMR 7504, BP 43, 67034 Strasbourg cedex 2, France

KEYWORDS: nickel fluoride, microemulsion, self-assembly, fluorination, nanoparticles

ABSTRACT. Super-structures or self-assembled nanoparticles open the development of new materials with improved and/or novel properties. Here, we present nickel fluoride $\left(\mathrm{NiF}_{2}\right)$ selfassemblies by successive preparatory methods. Originally, the self-assemblies were obtained by exploiting water-in-oil microemulsion technique as a result of auto-organization of hydrated

*Corresponding Authors e-mails: Pierre.M.Bonnet@uca.fr , hameedwazir@yahoo.co.uk 
$\mathrm{NiF}_{2}\left(\mathrm{NiF}_{2} \cdot 4 \mathrm{H}_{2} \mathrm{O}\right)$ nanoparticles. The nanostructuration of $\mathrm{NiF}_{2} .4 \mathrm{H}_{2} \mathrm{O}$ nanoparticles was confirmed from XRD and TEM data. The size and shape of $\mathrm{NiF}_{2} .4 \mathrm{H}_{2} \mathrm{O}$ nanoparticles, and their subsequent self-assemblies varied slightly as a function of water to surfactant and oil ratios. The SEM and TEM characterizations revealed that the nanoparticles are organized into a succession of self-assemblies: from individual nanoparticles assembled into layers to truncated bipyramids, which further auto-organized themselves into almond shaped super-structures. The anhydrous $\mathrm{NiF}_{2}$ was achieved by heating $\mathrm{NiF}_{2} .4 \mathrm{H}_{2} \mathrm{O}$ self-assemblies under the dynamic flow of molecular fluorine $\left(\mathrm{F}_{2}\right)$ at moderate temperature $\left(350^{\circ} \mathrm{C}\right)$. The preservation of self-assemblies during the transformation from $\mathrm{NiF}_{2} \cdot 4 \mathrm{H}_{2} \mathrm{O}$ to $\mathrm{NiF}_{2}$ is successfully achieved. The obtained materials have specific surface areas (SSA) about $30 \mathrm{~m}^{2} / \mathrm{g}$, more than $60 \%$ the value for bulk $\mathrm{NiF}_{2}$. The lithium ion $\left(\mathrm{Li}^{+}\right)$storage capacities and mechanism of the nanostructured samples were tested and compared with the bulk material by galvanostatic cycling and X-Ray Absorption Spectroscopy (XAS). The nanostructured samples show higher capacities $(\sim 650 \mathrm{mAh} / \mathrm{g})$ than the theoretical (554 $\mathrm{mAh} / \mathrm{g}$ ) first discharge capacity due to the concomitant redox conversion mechanism of $\mathrm{NiF}_{2}$ and solid-electrolyte interphase (SEI) formation. The nanostructuration by self-assembly appears to positively influence the lithium diffusion in comparison with the bulk material. Finally, magnetic properties of nanostructured $\mathrm{NiF}_{2} \cdot \mathrm{xH}_{2} \mathrm{O}(\mathrm{x}=0$, or 4$)$ have been measured and appear to be very similar to the corresponding bulk materials, without any visible size-reduction effect. The hydrated samples $\mathrm{NiF}_{2} \cdot 4 \mathrm{H}_{2} \mathrm{O}$ show an antiferromagnetic ordering at $\mathrm{T}_{\mathrm{N}}=3.8 \mathrm{~K}$, whereas the dehydrated ones $\left(\mathrm{NiF}_{2}\right)$ present a canted antiferromagnetic ordering at $\mathrm{T}_{\mathrm{N}}=74 \mathrm{~K}$. 


\section{INTRODUCTION}

Nanoscopic materials have been extensively explored - both on academic research and industrial levels - during the last couple of decades due to their novel and superior electrical, optical and structural properties over the conventional micro and macroscopic materials ${ }^{1-8}$. The characteristics of nanomaterials are primarily dependent on the size, shape and distribution of their nanoparticles ${ }^{9-11}$. Therefore, many materials have found renewed applications other than their classical uses. Assembling of particular size and shape nanoparticles into super architectures is critical for creation of functional nanomaterials having superior properties over the prevailing ones ${ }^{12-14}$. For example, ordered nanocrystals forming superlattices have been discovered for possible applications in magnetic and optical devices exploiting the quantum confinement effects ${ }^{15-17}$. Dense ceramics after sintering, and structures mimicking biomaterials are synthesized from ordered super-structures ${ }^{18}$. Furthermore, self-assembled nanoparticles have been explored for large number of technologically important materials - besides others including metals, alloys, oxides, and organic-inorganic hybrids ${ }^{19-22}$. Self-assembling process is either controlled and/or self-propagating ${ }^{23-24}$, and have been exploited for construction of superstructures of diverse materials through particularly designed synthesis protocols ${ }^{25-29}$.

After their historical applications in metallurgy, isotopic separation and optics ${ }^{30-32}$, interests in metal fluorides resurfaced at the turn of the century owing to their nanochemistry. This renewed attention has presented them as functional nanomaterials having applications in sensors, batteries, actuators, optical devices, optoelectronics and additives in lubricants besides others ${ }^{33-}$ ${ }^{36}$. New methods have been developed for synthesis of metal fluorides nanoparticles and their self-assembled super-structures. Water-in-oil microemulsion method has been also exploited for 
preparation of metal fluoride nanostructures ${ }^{37-38}$. Besides the simplicity of reaction apparatus and low temperature processing, reverse microemulsion technique comes up with a large degree of freedom to effectively control size, shape, distribution and auto-organization of nanoparticles in the resulting materials by slightly varying the synthesis parameters ${ }^{29,}{ }^{39-42}$. For example, selfassembled uniform nanoparticles of $\mathrm{YF}_{3}$ have been prepared by water in cyclohexane reverse microemulsion using polyoxyethylene(5)isooctylphenyl ether (NP-5) as surfactant ${ }^{43}$. Randomly distributed $\mathrm{BaF}_{2}$ nanoparticles were produced in a $\mathrm{CTAB} /$ water/isooctane reverse microemulsion ${ }^{38}$.

The benefits of nanostructuration by self-assembly for functional transition metals fluorides could be very interesting. However, no attention is paid to the synthesis of nanostructurated metal fluorides by reverse microemulsion probably due to the formation of hydrated compounds, and difficulty in dehydration of the resulting nanomaterials. Among the metal fluorides, an important effort is done on $\mathrm{FeF}_{3}^{44}$, but much less is done on compounds such as $\mathrm{CoF}_{2}$ or $\mathrm{NiF}_{2}$. Nevertheless, $\mathrm{NiF}_{2}$ is attracting attention as conversion reaction material for $\mathrm{Li}$ ion batteries due to its comparatively high voltage $(2.96 \mathrm{~V})$ and specific capacity $(554 \mathrm{mAh} / \mathrm{g})^{45}$. However, its poor electronic conductivity, due to the high ionicity of $\mathrm{Ni}-\mathrm{F}$ bond, is the main hurdle in its large scale applications as functional material in $\mathrm{Li}$ ion power storage devices ${ }^{7}$. Nonetheless, improvements in electrochemical properties of $\mathrm{NiF}_{2}$ have been reported by doping with $\mathrm{NiO}$, and also by preparation of nanocomposites with conductive carbon materials ${ }^{46}$. Furthermore, the electrochemical performances of $\mathrm{NiF}_{2}$ nanomaterials could be improved by engineering selfassemblies having specific open facets as seen with $\mathrm{CuO}^{47}$. Besides the electrochemical interests in nanostructured $\mathrm{NiF}_{2}$, the magnetic properties could also be interesting especially to see if $\mathrm{NiF}_{2}$ could exhibit different magnetic properties upon nanostructuration ${ }^{48}$. 
Here we come up with a new strategy to synthesize self-assembled nanoparticles of anhydrous $\mathrm{NiF}_{2}$. The final self-assembled super-structures were formed in a consequence to the successive auto-organization of different structures resulting of the individual nanoparticles auto-assembly in a $\mathrm{CTAB} / 2$-octanol/water reverse microemulsion system. The size and shape of self-assembled structures were controlled by varying the reaction duration, and water to surfactant $(\omega)$ and oil ( $\alpha$ ) molar ratios. The as synthesized $\mathrm{NiF}_{2} \cdot 4 \mathrm{H}_{2} \mathrm{O}$ nanomaterials were transformed to anhydrous $\mathrm{NiF}_{2}$, by an original conversion method under gaseous molecular fluorine $\left(\mathrm{F}_{2}\right)$ while preserving their self-assembly. The transformation is achieved at significantly lower temperature than previously reported ${ }^{49}$.

\section{EXPERIMENTAL}

\section{MATERIALS}

All the chemicals were purchased from commercial suppliers and used as such without further purification and/or treatments. The salts $\mathrm{Ni}\left(\mathrm{NO}_{3}\right)_{2} \cdot 6 \mathrm{H}_{2} \mathrm{O}$, and $\mathrm{NiCl}_{2} \cdot 6 \mathrm{H}_{2} \mathrm{O}$ and $\mathrm{NH}_{4} \mathrm{~F}$ were purchased of Normapur-VWR and Sigma-Aldrich, respectively. The surfactant, cetyltrimethylammonium bromide (CTAB), was used of Acros Organics and the oil, 2-octanol, was used of Sigma-Aldrich. Ethanol, absolute and commercial, was purchased from NormapurVWR.

\section{MATERIALS CHARACTERIZATIONS}

Powder X-Ray Diffraction (PXRD): XRD patterns of all the samples were recorded upon

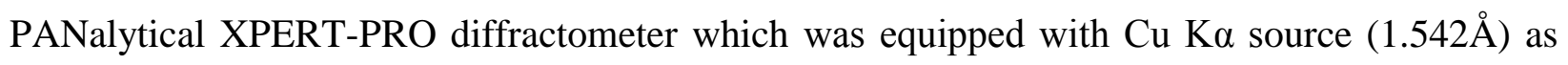


monochromator diffraction beam and a linear detector X'celerator. The scanning of the diffraction beams was performed in continuous steps each of size 0.0840 2theta and counting time of $180 \mathrm{~s}$. The crystallite size was estimated using the Scherrer's Equation (Eq. 1).

$\mathrm{d}=0.94 \lambda / \beta \cos \theta$

Where $\mathrm{d}$ corresponds to the crystallite and/or grain size, $\lambda$ is the wavelength - here $\lambda=1.542 \AA-$ of the $\mathrm{x}$-rays radiations used, $\beta$ is the corrected width of the respective peak in radians at full width at half maximum (FWHM), and $\theta$ is the diffraction angle of the respective peak in degrees.

Raman and Infra-Red spectroscopies: Raman scattering spectra were measured upon Raman spectrometer of JobinYvon model T64000. The wavelength of laser was $514.5 \mathrm{~nm}(2.41 \mathrm{eV})$ and the power was set at $100 \mathrm{~mW}$. The measurement was carried out in solid state by putting the sample powder upon glass slide under air at room temperature. The Fourier transformed Infrared (FTIR) spectra of all the samples were recorded in the mid IR regions upon Nicolet FTIR spectrometer from ThermoElectron Corporation in Attenuated Total Reflection (ATR) mode using SMART ORBIT accessory.

Thermogravimetry Analyses (TGA): TGA/DSC data of the hydrated nickel fluoride $\left(\mathrm{NiF}_{2} \cdot 4 \mathrm{H}_{2} \mathrm{O}\right)$ samples were collected under inert nitrogen $\left(\mathrm{N}_{2}\right)$ environment in the range of $25^{\circ} \mathrm{C}$ to $800^{\circ} \mathrm{C}$, at heating rate of $10^{\circ} \mathrm{C} / \mathrm{min}$ using TGA analyzer of SETARAM Instrumentations (model Setsys Evolution).

$77 \mathrm{~K}$ nitrogen sorption analysis: Sorption isotherms of powder samples were measured to determine specific surface area (SSA), pore size and volume, and pore size distribution using 
Micromeritics ASAP 2020. The samples were outgassed at room temperature for 24 hours prior surface area and porosity measurements.

Scanning Electronic Microscopy (SEM) and Transmission Electronic Microscopy (TEM): SEM images of the samples were taken using SUPRA 55VP ZEISS field-effect scanning electron microscope (FE-SEM) equipped with a Gemini ${ }^{\circledR}$ column and high efficiency secondary electron detector. The sample powders were dispersed upon carbon film and have been analyzed without further treatments. Samples were observed using a Hitachi Transmission Electron Microscope $(\mathrm{H}-7650)$ at $80 \mathrm{kV}$ acceleration voltage with magnifications up to $\mathrm{x} 200,000$. Images were taken using a Hamamatsu camera placed in a side position. The powders of the materials are investigated by TEM are suspended in ethanol and dropped on a 400 mesh holey carbon-coated copper grid and dried at room temperature in air.

Magnetic Measurements (SQUID): SQUID data were collected on a Quantum Design MPMS3 magnetometer. Magnetization measurements at different fields at a given temperature confirmed the absence of ferromagnetic impurities. Data were corrected for the sample holder and diamagnetism was estimated using Pascal constants.

Electrochemical Measurements: The electrochemical performances were investigated using galvanostatic discharges. The electrodes were composed of active material $(80 \% \mathrm{w} / \mathrm{w})$, acetylene black $(10 \% \mathrm{w} / \mathrm{w})$ and polyvinylidene difluoride (PVDF $10 \% \mathrm{w} / \mathrm{w})$ as binder. After stirring in propylene carbonate (PC), the mixture was spread uniformly onto a stainless steel current collector disk of $10 \mathrm{~mm}$ diameter. After the PC evaporation, the electrodes were dried in a vacuum oven at $120^{\circ} \mathrm{C}$ overnight to remove traces of water and solvent before their transfer into an argon-filled glovebox. The anode was a lithium metal disk, and the separator was Celgard 
2034. A two electrodes cell was used (Swagelok cell type), where lithium was both reference and counter electrodes. The electrolyte was $1.0 \mathrm{M} \mathrm{LiPF} 6$ in propylene carbonate/ethylene carbonate/dimethyl carbonate (PC/EC/3DMC; 1:1:3 vol. \%). The cells were assembled in an argon filled dried glove box. Relaxation was performed for at least 5 hours until the open circuit voltage (OCV) stabilization. Galvanostatic discharges, carried out on a VMP2-Z instrument from Biologic, were performed at room temperature by applying a constant current density of 10 $\mathrm{mA} / \mathrm{g}$ with a cutoff voltage of $1 \mathrm{~V}$ in reduction and $4.3 \mathrm{~V}$ in oxidation.

X-RAY Absorption Spectroscopy (XAS): X-ray absorption spectroscopy was carried out at beamline ROCK of SYNCHROTRON SOLEIL. The electrode samples were never exposed to the ambient environment during the measurement. Higher harmonics in the X-ray beam were minimized by detuning the $\mathrm{Si}(111)$ monochromator by $40 \%$ at the $\mathrm{Ni} \mathrm{K}$-edge $(8333 \mathrm{eV})$. Transmission spectra at the Ni K-edge were collected along with a simultaneous spectrum on a reference foil of metallic Ni to assure consistent energy calibration. Energy calibration was carried out by using the first derivatives in the spectra of Ni foil. Data were analyzed and refined using Artemis software.

\section{SYNTHESIS OF MATERIALS}

\section{$\mathrm{NiF}_{2} .4 \mathrm{H}_{2} \mathrm{O}$ NANOPARTICLES AND BULK MATERIAL.}

The $\mathrm{NiF}_{2} \cdot 4 \mathrm{H}_{2} \mathrm{O}$ nanoparticles were synthesized by reverse microemulsion technique following a

reported procedure ${ }^{38,50}$. In a typical synthesis process, a series of $\mathrm{NiF}_{2} \cdot 4 \mathrm{H}_{2} \mathrm{O}$ nanoparticles (water/oil molar ratio $\alpha \sim 0,96$ ) were synthesized by preparing water-in-oil microemulsions of identical compositions in two separate Teflon beakers by stirring together 0.014 mol of CTAB, 
$0.230 \mathrm{~mol}$ of 2-octanol and $0.222 \mathrm{~mol}$ of $\mathrm{H}_{2} \mathrm{O}$ for one hour. The water-in-oil microemulsions were named as microemulsion one $\left(\mu \mathrm{E}_{1}\right)$ and microemulsion two $\left(\mu \mathrm{E}_{2}\right)$ based on the facts that the former contained $0.002 \mathrm{~mol}$ of $\mathrm{Ni}\left(\mathrm{NO}_{3}\right)_{2} \cdot 6 \mathrm{H}_{2} \mathrm{O}$ and the latter contained $0.005 \mathrm{~mol}$ of $\mathrm{NH}_{4} \mathrm{~F}$. The $\mu \mathrm{E}_{1}$ and $\mu \mathrm{E}_{2}$ microemulsions are stirred individually for one hour and are stable after stopping the stirring, no segregation of the aqueous and organic phases has been observed After, the two microemulsions were mixed by pouring down very slowly $\mu \mathrm{E}_{1}$ into $\mu \mathrm{E}_{2}$.. After mixing the two microemulsions, the whole reaction mixture was stirred, at room temperature, for another $15 \mathrm{~min}$ (sample "1"), $30 \mathrm{~min}$ (sample "2") and $60 \mathrm{~min}$ (sample "3"). The green colored precipitate obtained in the bottom of the reaction beaker was separated from the supernatant by centrifuging at 4000 revolutions per minute (rpm) for 30 minutes. To ensure complete removal of the unutilized surfactant, oil, water and any other contamination(s), the resulting green powder was washed subsequently with $10 \mathrm{~mL}$ of ethanol and distilled water followed by centrifugation at $4000 \mathrm{rpm}$ for 10 minutes. The washing process was repeated ten times. The thoroughly washed green powder was dried at room temperature for 24 hours.

Another series of $\mathrm{NiF}_{2} .4 \mathrm{H}_{2} \mathrm{O}$ nanoparticles (water/oil molar ratio $\alpha \sim 1.21$ ) was synthesized following the procedure described in the preceding paragraph by increasing the water contents in microemulsions $\left(\mu \mathrm{E}_{1}\right.$ and $\mu \mathrm{E}_{2}$ ) to 0.278 moles, and stirring the reactions after mixing of the two microemulsions for 15 min (sample "4"), 30 min (sample "5") and 60 min (sample "6").

Attempts were also made for the synthesis of $\mathrm{NiF}_{2} \cdot 4 \mathrm{H}_{2} \mathrm{O}$ nanoparticles at decreased water contents (0.167 mol, water/oil molar ratio $\alpha \sim 0.7)$. However, due to the instability, quite unusual, of the resulting microemulsions $\left(\mu \mathrm{E}_{1}\right.$ and $\left.\mu \mathrm{E}_{2}\right)$, the syntheses were not followed. A small amount of powder was isolated in one of the cases, and characterized by different analytical techniques 
(XRD, FTIR, Raman, TEM and SEM data are given in Figure S1(a-f) in the supplementary information (SI)). Because, microemulsions of this series were not stable, these samples will not be discussed here. Generally the microemulsions are stable over a long range of water contents, which is not the case here. The use of any suitable co-surfactant, which allows to favorably dispersing the water by decreasing the interfacial tension, would enhance stability of the microemulsion ${ }^{51}$.

Bulk $\mathrm{NiF}_{2} \cdot 4 \mathrm{H}_{2} \mathrm{O}$, labeled "bulk-1", was synthesized by a classical reaction in water with aqueous hydrogen fluoride $\left(\mathrm{HF}_{\mathrm{aq}}\right)$. Hydrated nickel chloride $\left(\mathrm{NiCl}_{2} \cdot 6 \mathrm{H}_{2} \mathrm{O}\right)$ was added to a large excess of $48 \% \mathrm{HF}_{\mathrm{aq}}$ in a Teflon beaker. The reaction mixture was stirred at $50^{\circ} \mathrm{C}$ followed by evaporation of the excess $\mathrm{HF}_{\mathrm{aq}}$ by extractor. The resulting green colored $\mathrm{NiF}_{2} \cdot 4 \mathrm{H}_{2} \mathrm{O}$ powder was dried at room temperature under fume hood and then stored in a clean vial. A complete summary of the synthesis protocol and parameters of the samples "1"-"6" (Scheme S1 and Table S1) are presented in Supporting Information (SI).

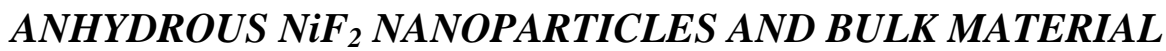

The $\mathrm{NiF}_{2}$ nanoparticles were synthesized in a two steps process by the dehydration of $\mathrm{NiF}_{2} \cdot 4 \mathrm{H}_{2} \mathrm{O}$ nanoparticles. In first step, a weighed amount of hydrated nickel fluoride powder $\left(\mathrm{NiF}_{2} \cdot 4 \mathrm{H}_{2} \mathrm{O}\right.$ nanoparticles) was placed in a nickel boat which was then inserted into the chamber of Buchi Incorporation vacuum drying system. Upon achieving the target vacuum, the chamber was heated to $100^{\circ} \mathrm{C}$ and maintained for one hour. Afterwards, the temperature of the chamber was raised to $250^{\circ} \mathrm{C}$ and maintained for another five hours. At the end of the process the system was allowed to cool down naturally to room temperature. The color of powder turned yellow from 
green ${ }^{52}$. The purposely designed procedure was followed to get transformed $\mathrm{NiF}_{2} \cdot 4 \mathrm{H}_{2} \mathrm{O}$ to $\mathrm{NiF}_{2}$ successfully while retaining the basic shapes and structures of the self-assembled nanoarchitectures synthesized by microemulsion. The temperature regimes for the separately manipulated steps were decided following the TGA curve of bulk and $\mathrm{NiF}_{2} \cdot 4 \mathrm{H}_{2} \mathrm{O}$ nanoparticles. TGA curve of bulk sample is given in Figure S2 which shows a main weight loss between $100^{\circ} \mathrm{C}$ and $300^{\circ} \mathrm{C}$ with a maximum at approximately $163.3^{\circ} \mathrm{C}$. At this temperature, $\mathrm{NiF}_{2} \cdot 0.3 \mathrm{H}_{2} \mathrm{O}$ is achieved and the remaining $0.30 \mathrm{H}_{2} \mathrm{O}$ molecules per formula unit are released in the steady and continuous step up to $340^{\circ} \mathrm{C}$.

In a second step, the nickel boat containing the vacuum dried and/or partially dehydrated powder of the sample was inserted into the chamber of fluorination furnace. The furnace was purged with dry $\mathrm{N}_{2}$ gas for two hours and then heated at the rate of $5^{\circ} \mathrm{C} / \mathrm{min}$ to reach the target temperature of $350^{\circ} \mathrm{C}$. When the temperature reached $250^{\circ} \mathrm{C}, \mathrm{N}_{2}$ supply was disconnected and pure $F_{2}$ gas was allowed to enter the furnace chamber. The dynamic fluorination was continued at $350^{\circ} \mathrm{C}$ for five hours. Afterwards, the $\mathrm{F}_{2}$ supply was stopped and $\mathrm{N}_{2}$ was opened into the chamber. The chamber was allowed to cool down to room temperature naturally under gaseous $\mathrm{N}_{2}$ environment. Finally, dehydrated nickel fluoride $\left(\mathrm{NiF}_{2}\right)$ powder was retrieved into a clean vial. The same procedure was repeated for the transformation of all $\mathrm{NiF}_{2} \cdot 4 \mathrm{H}_{2} \mathrm{O}$ samples " 1 ", " 2 ", “3", “4”, "5" and "6" to $\mathrm{NiF}_{2}$ samples labeled "1-1", "2-2", “3-3", “4-4", "5-5" and "6-6", respectively. The cartoon drawing of the furnace used for the dehydration of hydrated nickel fluorides is given in Figure S3 and the relevant dehydration parameters are summarized in Table S2.

The procedure for synthesis of bulk dehydrated nickel fluoride $\left(\mathrm{NiF}_{2}\right)$, labeled "bulk-2", is exactly the same as was adopted for the preparation of dehydrated nano- $\mathrm{NiF}_{2}$ from hydrated 
nickel fluorides nanoparticles $\left(\mathrm{NiF}_{2} \cdot 4 \mathrm{H}_{2} \mathrm{O}\right)$. The synthesis parameters and samples labels of all the obtained samples are summarized in Table 1.

Table 1. Summary of the main synthesis parameters and samples labels of $\mathrm{NiF}_{2} \cdot 4 \mathrm{H}_{2} \mathrm{O} / \mathrm{NiF}_{2}$ nanoparticles and bulk material.

\begin{tabular}{|c|c|c|c|c|c|}
\hline Sample & $\begin{array}{c}\mathrm{H}_{2} \mathrm{O} / \text { Oil } \\
\alpha \\
\text { (mole/mole) }\end{array}$ & $\begin{array}{l}\text { Time } \\
\text { (Min) }\end{array}$ & Sample & $\begin{array}{c}\text { Heating under Vacuum } \\
\text { Temp./Time } \\
\left({ }^{\circ} \mathrm{C} / \mathrm{H}\right)\end{array}$ & $\begin{array}{c}\text { Fluorination } \\
\text { Temp./Time } \\
\left({ }^{\circ} \mathbf{C} / \mathbf{H}\right)\end{array}$ \\
\hline$" 1 "$ & 0.96 & 15 & "1-1" & $250 / 5$ & $350 / 5$ \\
\hline$" 2 "$ & 0.96 & 30 & “2-2" & $250 / 5$ & $350 / 5$ \\
\hline "3" & 0.96 & 60 & “3-3" & $250 / 5$ & $350 / 5$ \\
\hline "4" & 1.21 & 15 & “4-4" & $250 / 5$ & $350 / 5$ \\
\hline "5" & 1.21 & 30 & “5-5" & $250 / 5$ & $350 / 5$ \\
\hline "6" & 1.21 & 60 & “6-6" & $250 / 5$ & $350 / 5$ \\
\hline "Bulk-1" & - & -- & "Bulk-2" & $250 / 5$ & $350 / 5$ \\
\hline
\end{tabular}

\section{RESULTS AND DISCUSSION}

\section{$\mathrm{NIF}_{2} \cdot 4 \mathrm{H}_{2} \mathrm{O}$ NANOPARTICLES AND THEIR SELF-ASSEMBLIES.}

The $\mathrm{NiF}_{2} \cdot 4 \mathrm{H}_{2} \mathrm{O}$ nanoparticles and their self-assemblies were prepared at two different values of $\omega$ (molar water/surfactant ratio) i.e., 16.18 and 20.23 following the reported procedures ${ }^{38,50}$. Simultaneously, the water/oil molar ratio is changed from $\alpha<1(\sim 0.96)$ to $\alpha>1(\sim 1.21)$ for the $\mathrm{NiF}_{2} .4 \mathrm{H}_{2} \mathrm{O}$ nanoparticle series prepared at $\omega=16.2$ and $\omega=20.2$, respectively. As presented in Table S1, samples were obtained by varying the $\omega$ and reaction time from 15 min (sample " 1 ") to $30 \min$ (sample "2") to 60 min (sample “3”). 
Powder X-Rays Diffraction (XRD) patterns of all the samples ("1" to " 6 " and "Bulk-1") are presented in Figure 1-a. The XRD patterns give narrow and intense peaks at $2 \theta$ positions matching with the powder diffraction files (PDF) of $\mathrm{NiF}_{2} \cdot 4 \mathrm{H}_{2} \mathrm{O}([00-025-0579]$ and [04-0089585]) in ICDD (International Center for Diffraction Data) database. The search and match results confirm the orthorhombic crystal system with $\mathrm{P}_{1}$ ab space group of $\mathrm{NiF}_{2} .4 \mathrm{H}_{2} \mathrm{O}$ crystals. The intense and narrow peaks indicate the formation of well grown crystallites of $\mathrm{NiF}_{2} \cdot 4 \mathrm{H}_{2} \mathrm{O}$ in all the samples. The crystallite sizes were estimated by Scherrer's approximation (Eq. 1), and presented in Table 2. As evident from Table 2, the crystallite size increases slightly with increasing $\omega$ and the reaction time. This was anticipated and in accordance to the previous reports about the effect of water contents over the crystallite and/or grain $\operatorname{size}^{53}$, but in our case the effect is smaller. In fact, the increase in water content is responsible for increasing the droplet size and thus, decreasing its rigidity ${ }^{54}$. The decrease in droplet rigidity enhances the exchange rate (diffusion rate) which is responsible for fast growths of crystals ${ }^{55}$. However, certain other factors could also influence particle nucleation and growth, among them inter-micellar interactions and dynamic behavior, phase behavior (e.g. solubility), average occupancy of the water pool by the reactant (i.e., precursor concentration) can be cited. The use of cationic CTAB as surfactant can especially influence the packing parameter and the interfacial rheology, due to interaction with precursor salts. In our case, while some parameters may lead to faster kinetics, some others favor slower kinetics. As a global result, the size of the primary particles remains nearly unaffected ${ }^{56-57}$. It is pertinent to mention here that though the increase in crystallite size with increasing water contents is slight but the overall crystallite size is quite very small compared to that reported previously in case of $\mathrm{BaF}_{2}$ by the very same water-in-oil microemulsion system ${ }^{38}$. 

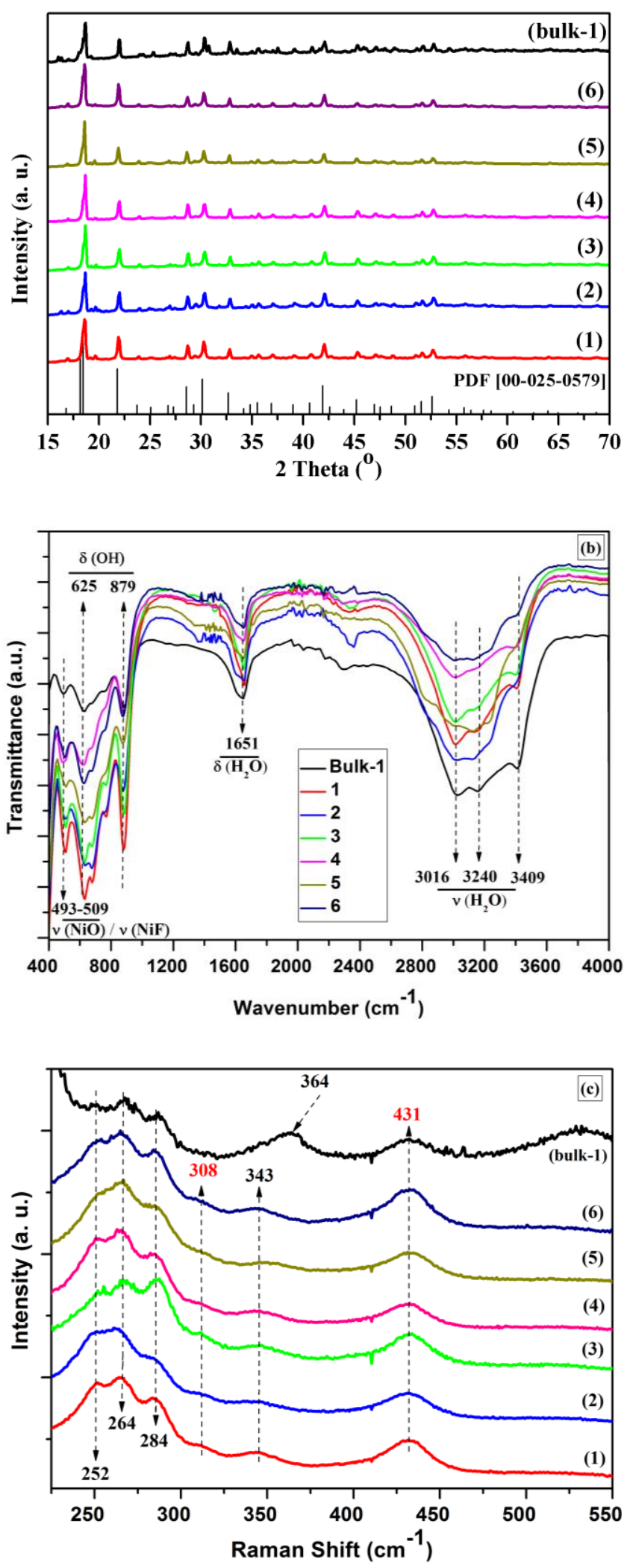
Figure 1. (a) XRD patterns, (b) FTIR and (c) Raman spectra of bulk ("bulk-1) and nano$\mathrm{NiF}_{2} .4 \mathrm{H}_{2} \mathrm{O}$ samples (" 1 " to "6") synthesized respectively by the reaction with $\mathrm{HF}_{\mathrm{aq}}$, and waterin-oil microemulsion technique under varying $\omega$ and $\alpha$ ratios and reaction time.

The obtained $\mathrm{NiF}_{2} \cdot 4 \mathrm{H}_{2} \mathrm{O}$ nanoparticles are confirmed by FTIR and Raman analyses. FTIR spectra of $\mathrm{NiF}_{2} \cdot 4 \mathrm{H}_{2} \mathrm{O}$ bulk and nanoparticles are presented in Figure 1-b. The FTIR spectra of the $\mathrm{NiF}_{2} \cdot 4 \mathrm{H}_{2} \mathrm{O}$ nanoparticles are in good agreement with the IR spectrum of bulk $\mathrm{NiF}_{2} \cdot 4 \mathrm{H}_{2} \mathrm{O}$ embedded in Figure 1-b, and also with the previously reported ${ }^{58}$. The mid FTIR spectra of $\mathrm{NiF}_{2} .4 \mathrm{H}_{2} \mathrm{O}$ bulk and nanoparticles give stretching and bending peaks for $\mathrm{O}-\mathrm{H}$ of $\mathrm{H}_{2} \mathrm{O}$ in the range of $3409-3016 \mathrm{~cm}^{-1}$ and $1651 \mathrm{~cm}^{-1}$, respectively ${ }^{59-61}$. The peaks which are absent in the FTIR spectrum of "bulk-1" and appear at $2816 \mathrm{~cm}^{-1}, 1466 \mathrm{~cm}^{-1}$ and $1396 \mathrm{~cm}^{-1}$ in the FTIR spectra of samples "1"-“6" are corresponded to the adsorbed surfactant molecules. The fewer than actual peaks of pure CTAB is the indication of the fact that the surfactant molecules are in strong interaction with $\mathrm{NiF}_{2} \cdot 4 \mathrm{H}_{2} \mathrm{O}$ nanoparticles ${ }^{62}$. The weak peak around $2330 \mathrm{~cm}^{-1}$ in FTIR spectra of all the samples is ascribed to the combination of bending and rocking vibrations of $\mathrm{H}_{2} \mathrm{O}^{58}$. A number of peaks appear in the FTIR spectra of bulk as well as nanoparticles in the 900 $\mathrm{cm}^{-1}$ to $400 \mathrm{~cm}^{-1}$ region. The two peaks of medium intensity at $879 \mathrm{~cm}^{-1}$ and $764 \mathrm{~cm}^{-1}$ are due to the rocking while the other two peaks of comparatively weak intensity at $679 \mathrm{~cm}^{-1}$ and $632 \mathrm{~cm}^{-1}$ correspond to the wagging vibrations of $\mathrm{H}_{2} \mathrm{O}^{58}$. The peak around $509 \mathrm{~cm}^{-1}$ is assigned to the NiF stretching vibration ${ }^{58}$. The IR spectra of metal fluoride nanoparticles prepared from nitrate salts can show significant peaks for $\mathrm{NO}_{3}^{-}$stretching vibrations around $1384 \mathrm{~cm}^{-1}$. However, the IR spectra of all the samples do not contain peaks of $\mathrm{NO}_{3}{ }^{-}$. The samples were also analyzed by Raman spectroscopy in the range of $600 \mathrm{~cm}^{-1}-300 \mathrm{~cm}^{-1}$ at room temperature under air. The Raman spectra (Figure 1-c) of all the samples correspond to each other. The peaks at $431 \mathrm{~cm}^{-1}$ 
and $308 \mathrm{~cm}^{-1}$ corresponds to $\mathrm{A}_{1 \mathrm{~g}}$ and $\mathrm{E}_{\mathrm{g}}$ vibration modes of $\mathrm{NiF}_{2}$, respectively ${ }^{63}$. The rest of the peaks are due to the different vibration modes of $\mathrm{Ni}-\mathrm{O}$ bond and $\mathrm{H}_{2} \mathrm{O}$, and symmetric stretching mode of hydrogen bond ${ }^{64-65}$.

Table 2. Crystallite and individual particle sizes of $\mathrm{NiF}_{2} \cdot 4 \mathrm{H}_{2} \mathrm{O}$ and $\mathrm{NiF}_{2}$ nanoparticles and their bulk counterparts determined by XRD and TEM respectively.

\begin{tabular}{|c|c|c|c|c|c|}
\hline \multirow{2}{*}{$\begin{array}{l}\text { Sampl } \\
\text { e }\end{array}$} & \multicolumn{2}{|c|}{$\begin{array}{c}\text { Crystallite/Individual Particle } \\
\text { size }\end{array}$} & \multirow{2}{*}{ Sample } & \multicolumn{2}{|c|}{$\begin{array}{c}\text { Crystallite/Individual Particle } \\
\text { size }\end{array}$} \\
\hline & $\begin{array}{l}\text { XRD } \\
(\mathbf{n m})\end{array}$ & $\begin{array}{l}\text { TEM } \\
(\mathbf{n m})\end{array}$ & & $\begin{array}{l}\text { XRD } \\
(\mathbf{n m})\end{array}$ & $\begin{array}{l}\text { TEM } \\
(\mathbf{n m})\end{array}$ \\
\hline$" 1 "$ & 15.2 & $15.7 \pm 4.3$ & "1-1" & $13.4 \pm 0.7$ & $24.0 \pm 8.0$ \\
\hline$" 2 "$ & 16.8 & $17.3 \pm 4.1$ & “2-2" & $14.2 \pm 2.0$ & $26.0 \pm 2.5$ \\
\hline "3" & 17.9 & $19.2 \pm 8.4$ & “3-3” & $14.3 \pm 2.4$ & $26.8 \pm 4.6$ \\
\hline$" 4 "$ & 18.3 & $18.9 \pm 6.4$ & “4-4" & $14.8 \pm 2.2$ & $31.4 \pm 3.2$ \\
\hline "5" & 20.8 & $20.1 \pm 9.4$ & “5-5” & $14.2 \pm 2.0$ & $13.6 \pm 3.2$ \\
\hline "6" & 24.4 & $23.0 \pm 7.1$ & “6-6" & $15.7 \pm 2.9$ & $29.9 \pm 4.6$ \\
\hline "Bulk-1" & 48.1 & $>250^{(\mathrm{i})}$ & "Bulk2" & $37.2 \pm 22.1$ & $>250$ \\
\hline
\end{tabular}

(i) irregular shaped particles spread over a wide range of size

SEM images of samples " 1 " to " 3 " and " 4 " to " 6 " are presented in Figure 2 and Figure 3, respectively. SEM images of sample " 1 " $(\omega=16.18, \alpha<1$ and reaction time of 15 min) show predominant and larger structures having almond-like shapes, and less frequent and smaller truncated bi-pyramidal structures (Figure 2-a, b). The almond-like structure looks anisotropic having average length and width in order of 6-7 $\mu \mathrm{m}$ and 3-4 $\mu \mathrm{m}$, respectively. However, the truncated bi-pyramids seem isotropic having average size of 5-6 $\mu \mathrm{m}$. The bi-pyramids seem to be formed as a result of auto-assembling of smaller structures perhaps cubes (Figure $2 b$ inset). Furthermore, the truncated faces of the bi-pyramids are rough while the isosceles trapezoid facets 
are smooth. This could be due to the slow growth rate along z-axis direction (vertical) and rapid growth rate along $\mathrm{x}$ - and $\mathrm{y}$-axis directions (horizontal). The morphologies of sample "2" (Figure 2-c, d) and "3" (Figure 2-e, f) are not too different than that of sample "1". The same larger almond shape and smaller truncated bi-pyramidal structures are also seen in the SEM images of sample " 2 " and " 3 ". However, as the reaction time - at same $\omega$ and $\alpha$ ratios - increases from 15 min (sample "1") to 60 min (sample "3"), the size of almond shaped structure increases slightly from the order of 6-7 $\mu \mathrm{m}$ to 7-7.5 $\mu \mathrm{m}$. The magnified SEM images of sample "2" (Figure 2-d) and "3" (Figure 2-f) show a cascade auto-organization of the cubes into truncated bi-pyramids which further auto-organize into almond shaped macrostructures. 

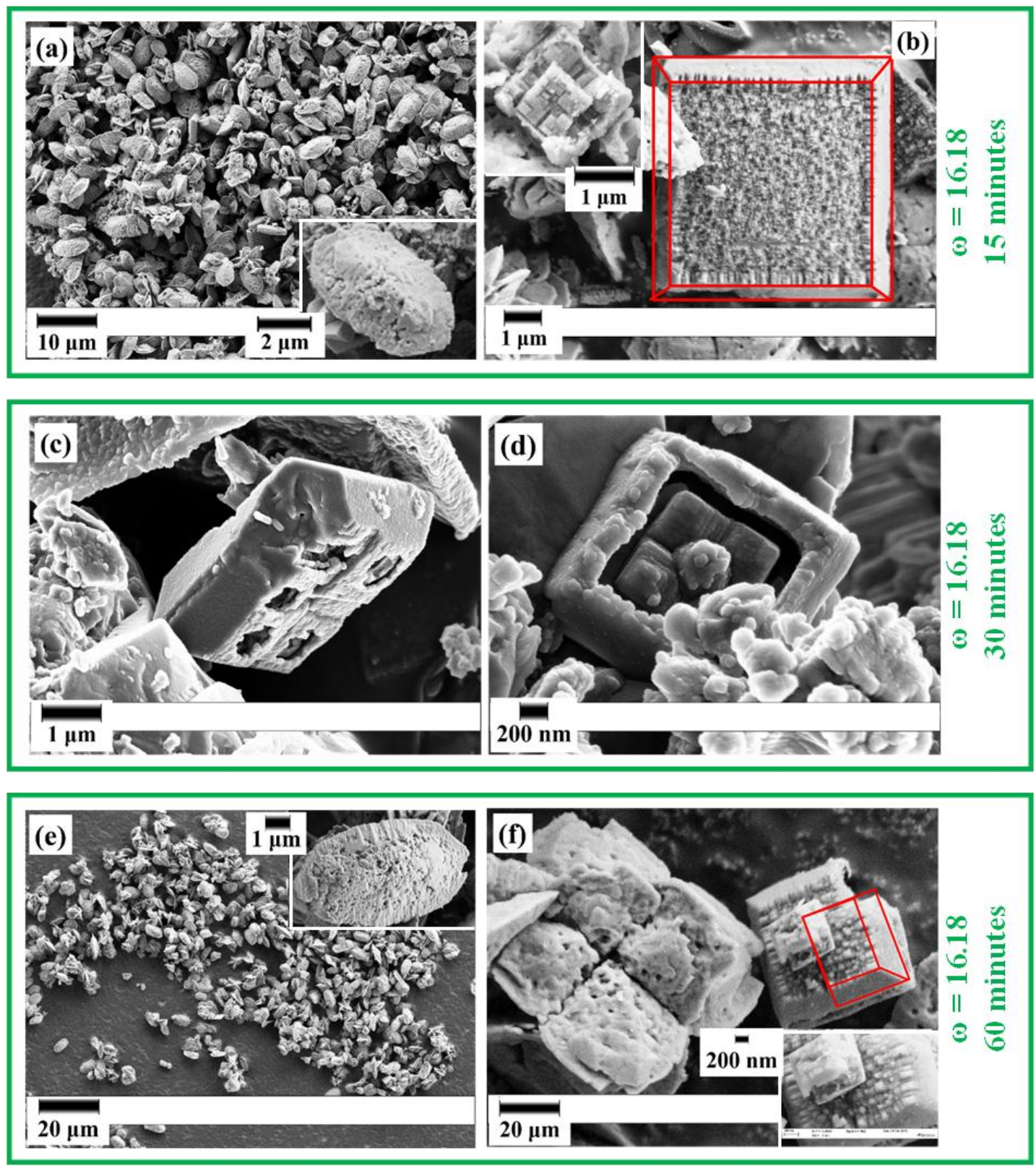

Figure 2. SEM images showing almond-like structures of samples "1" (a) and "3" (e), truncated bipyramids of samples " 1 " (b), " 2 " (c) and " 3 " (f), incomplete pyramidal wall encompassing auto-organized small pyramids of sample " 2 " (d), and auto-organized truncated bipyramids into superstructure of sample "3" (f); insets in (a) and (e) show magnified almond-like structures of samples " 1 " and " 3 ", respectively 
Upon increasing the $\omega$ from 16.18 and $\alpha<1$ (samples "1" to " 3 ") to $\omega=20.23$ and $\alpha>1$ (samples "4" to "6"), variations in morphologies of the resulting $\mathrm{NiF}_{2} \cdot 4 \mathrm{H}_{2} \mathrm{O}$ nanomaterials are observed in the SEM images (Figure 3-a-f). As shown in Figure 3-a, the SEM image of sample " 4 " $(\omega=$ 20.23, $\alpha>1$ and reaction time of $15 \mathrm{~min}$ ) shows truncated bi-pyramids which are highly agglomerated through the isosceles facets. The average size of the truncated bi-pyramids is in the order of $8-8.5 \mu \mathrm{m}$. The rupture running along the center of the truncated bi-pyramidal shapes indicates that the structures are not fully developed to form well defined almond-like structures (Figure 3-b and 3-b inset). However, the SEM images of samples "5" (Figure 3-c) and "6" (Figure 3-e) show the very almond shaped structures which upon magnification resembling boats covered on both the sides by vertically standing truncated bi-pyramids. The sizes of the almondlike structures formed in sample "5" and " 6 " are in the order of 19-20 $\mu \mathrm{m}$ and 22-23 $\mu \mathrm{m}$, respectively, and are far larger than those of samples "1" to " 3 ". The surfaces of almonds-like assemblies are covered on both the sides by truncated bi-pyramidal structures as shown in Figure 3-d (sample "5") and 3-f (sample "6"). In fact, the almond-like super-structures are formed as a result of horizontal auto organization of truncated bi-pyramids, and after attaining a threshold size of the almond-like structures, the horizontal growth stops on the expense of a new growth initiation on the high energy truncated facets of almonds. The truncated bi-pyramidal structures are aligned through the truncated facets owing to interdigitation of surfactant molecules ${ }^{29}$. 

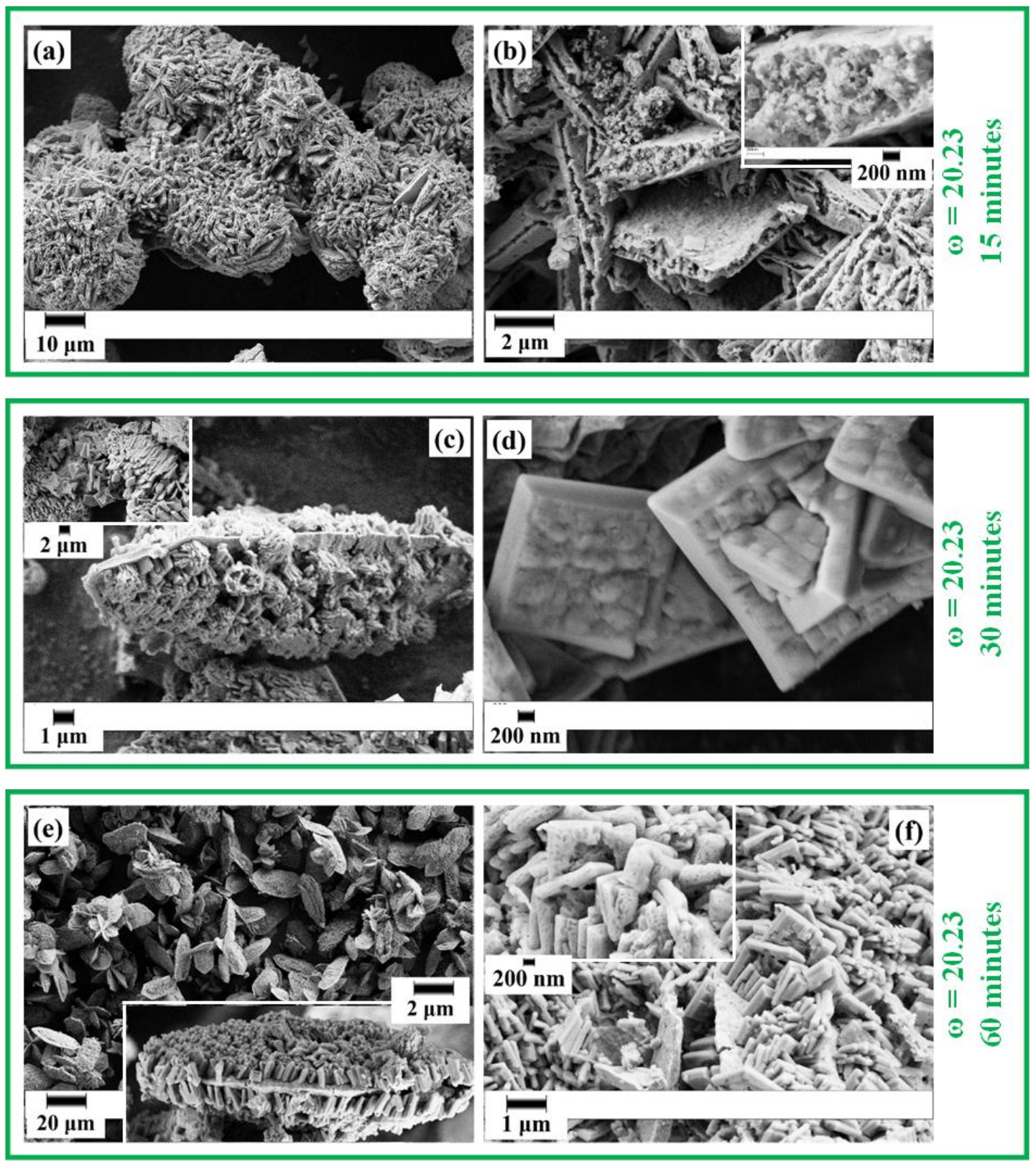

Figure 3. SEM images showing agglomerated truncated bi-pyramids of sample "4" (a), large almonds super-structures covered with sub-structures of samples "5" (c) and "6" (e), underdeveloped truncated bi-pyramids of samples "4" (b) and well organized through truncated facets truncated bi-pyramids of samples " 5 " (d) and " 6 " (f); inset in (b) shows magnification of rupture in truncated bi-pyramids of sample "4", in (e) magnification of a super-structure of 
sample " 6 " and in (f) magnification of auto-organized through truncated facets truncated bipyramids of sample " 6 ".

TEM images of samples "1" to "3" $(\omega=16.18, \alpha<1)$ are presented in Figures 4. Figure 4-a TEM image of sample "1" - shows an elongated hexagonal super-structure (length $=3.37 \mu \mathrm{m}$ and width $=1.94 \mu \mathrm{m}$ ). A small square $1 / 4$ the size of hexagon is also seen. The square structure has a cleavage along the diagonal, and seems to be formed of single layer of nanoparticles in the center while a second layer growth is observed on the edges. It seems that the cleaved square particle is the result of auto-assemblage of nanoparticles. This hypothesis of nanoparticles autoassemblage into square is further augmented by the larger magnification TEM image (Figure 4b) showing self-assembled nanoparticles in horizontal layers which are packed successively into a cuboid structure (Figure 4-b inset). In fact, the cuboids and the hexagons are not two different structures formed, but the hexagonal architecture is the result of further auto-organization of the cuboids. In fact, these structures can be assimilated respectively to the almond-like (hexagons) and truncated bi-pyramid (cuboids) structures observed in the SEM pictures. TEM images of sample " 2 " $\left(\mathrm{NiF}_{2} \cdot 4 \mathrm{H}_{2} \mathrm{O}\right.$ synthesized at $\omega=16.18, \alpha<1$ and reaction time of $\left.30 \mathrm{~min}\right)$ and " 3 " $\left(\mathrm{NiF}_{2} \cdot 4 \mathrm{H}_{2} \mathrm{O}\right.$ synthesized at $\omega=16.18, \alpha<1$ and reaction time of $\left.60 \mathrm{~min}\right)$ in Figure 4-c and Figure 4-e, respectively, also show similar structures i.e. larger hexagonal and their approximately $1 / 4$ square shaped as were observed in TEM images of sample "1". The average size of hexagons and cuboids are increasing upon increasing the reaction time at the same $\omega$ and $\alpha$ ratio. This is in good agreement with the sizes evolution observed in the SEM images (Figure 2) for the almondlike and truncated bi-pyramid structures. For example the average lengths and widths of hexagons of sample " 2 " $(11.67 \mu \mathrm{m}$ and $5.36 \mu \mathrm{m})$ and " 3 " $(13.70 \mu \mathrm{m}$ and $7.47 \mu \mathrm{m})$ are longer than 
that of sample " 1 " $(3.37 \mu \mathrm{m}$ and $1.94 \mu \mathrm{m})$. Similarly the average size of squire measured for sample " 2 " $(2.62 \mu \mathrm{m})$ and "3" $(3.18 \mu \mathrm{m})$ are larger than sample " 1 " $(1.25 \mu \mathrm{m})$. Furthermore, the relatively compact cuboids and hexagons shown in TEM images of sample " 2 " and " 3 " suggest that the auto-assemblage efficiency of nanoparticles increases with increasing reaction time. The self-assembling of nanoparticles in sample "2" and "3" seems to have followed the same mechanism as was observed in sample " 1 ". The successive (vertical) growth indicated in Figure 4-d (inset) and 4-f (inset) further support the layer by layer growth mechanisms in sample " 2 " and sample "3", respectively. The individual particle size increases slightly as a function of increasing reaction time from $15 \mathrm{~min}$ to 30 to $60 \mathrm{~min}$ (Table 1 ). 

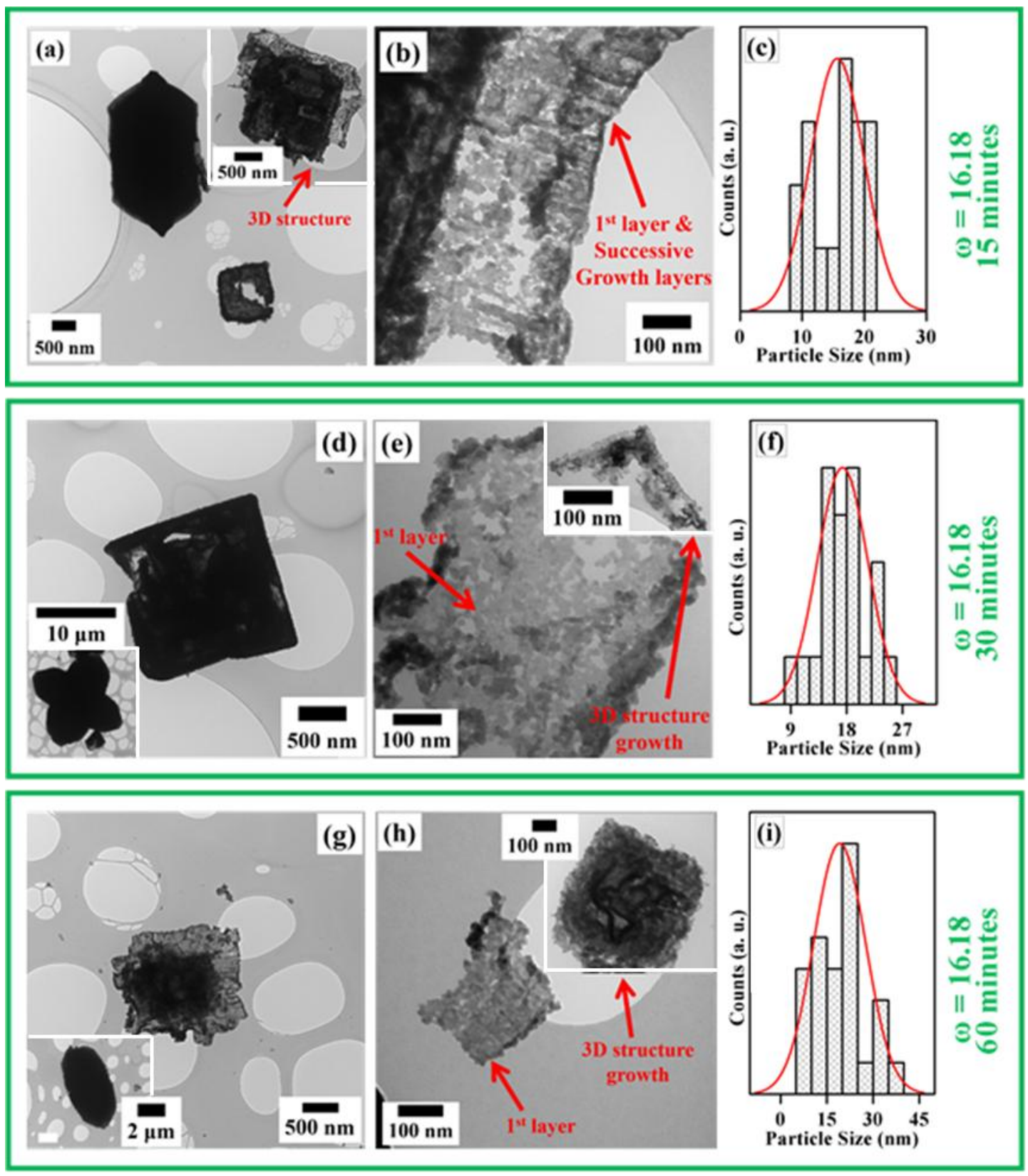

Figure 4. TEM images of samples " 1 ” (a, b), “2” (d, e), and " 3 " (g, h); the histograms (c), (f) and (i) are the particle size distributions of the samples "1", "2", and " 3 " respectively; insets in (a), (e), and (h) are the layer by layer formed 3D structures of samples " 1 ", "2", and “3", respectively. Insets in (d) and (g) are almond-like structures observed in samples "2" and "3" respectively. 
TEM images of samples " 4 " to "6" synthesized by microemulsion having larger water contents $(\omega=20.23$ and $\alpha>1)$ are given in Figure 5. The increase in $\omega$ from 16.18 to 20.23 resulted in formation of distorted-hollow-spherical $\mathrm{NiF}_{2} \cdot 4 \mathrm{H}_{2} \mathrm{O}$ structures as primary auto-assemblies of individual nanoparticles, a phenomenon which was not observed in case of sample "1" - " 3 ". The deformation in shapes of hollow spheres could be correlated to their coalescence and thus formation of larger irregular hollow nanostructures. The coalescence increases with increasing reaction time as is evident from the TEM images in Figure 5-a - e. The increase in $\omega$ from 16.18 to 20.23 resulted in different first self-assemblies. However, the consequent (second) selfassemblies of the hollow nanostructures followed the auto-organization mechanism observed in case of sample "1" to " 3 ". The deformed hollow nanostructures self-assemble into layers which packed successively to give 3D architectures. The TEM images given in Figure 5-b and 5-d of the samples " 4 " and "5", respectively, show partial self-assemblies. However, cuboid structure is observed in TEM image of sample "6" (Figure 5-f). Furthermore, the existence of hexagon like shape in TEM image of sample "6" (Figure 5-f inset) indicates that the cuboids further autoorganize as was the case in samples "1" to " 3 ". As indicated in the case of samples "1"-"3", the hexagons and cuboids observed here correspond respectively to the almond-like and truncated bi-pyramids structures observed in the SEM images (Figure. 3). In fact, the hollow-spherical nanostructures auto-assemble in case of samples " 4 " to " 6 " but the packing efficiencies are not high enough to resist their disorganization induced by the sonication performed during sample preparation for TEM analysis. On the other hand, nanoparticles in the first assemblies (distorted hollow spheres) are coherent, and thus remain intact as shells of hollow spheres after sonication. The $\mathrm{NiF}_{2} \cdot 4 \mathrm{H}_{2} \mathrm{O}$ nanoparticle size estimation from the TEM images of samples "4" to "6" is difficult due to stronger aggregation of the particles than for samples " 1 " to " 3 ". However, the 
particle size estimated from the thickness of the walls of the hollow spheres of sample " 4 " to " 6 " indicates that the size of individual nanoparticles increases slightly but consistently with the increasing $\omega$ and the reaction time. For example, as also shown in Table 2, the average nanoparticle sizes estimated from TEM images for the samples "1" to "3" and" 4 " to"6" are $15.7 \pm 4.3 \mathrm{~nm}$ to $19.2 \pm 8.4 \mathrm{~nm}$, and $18.9 \pm 6.4 \mathrm{~nm}$ to $23.0 \pm 7.1 \mathrm{~nm}$, respectively.

The bulk material synthesized is obtained with irregular shape and non-uniform big chunk shown by the TEM images (supplementary Figure S4). 

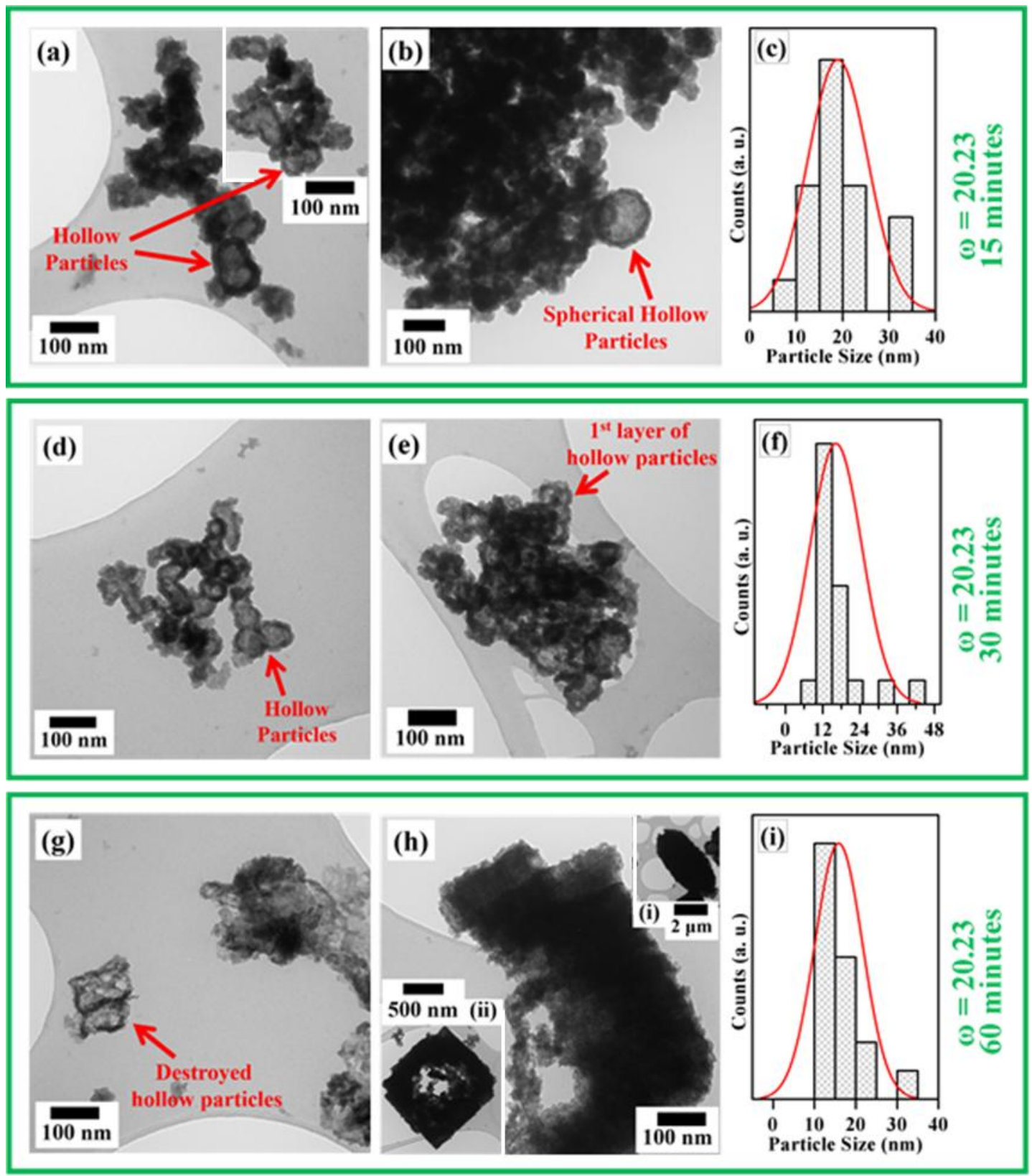

Figure 5. TEM images of samples " 4 " (a, b), " 5 " (d, e), and " 6 " (g, h); inset in (a) shows the successive layers of deshaped-hollow-spheres; insets in (h) show the cuboid and almond-like structures. The histograms (c), (f) and (i) are the particle size distributions of the samples "1", "2", and "3" respectively. 
An auto-organization mechanism is proposed in Figure 6. The formation of $\mathrm{NiF}_{2} \cdot 4 \mathrm{H}_{2} \mathrm{O}$ nanoparticles in the two series (samples " 1 " to " 3 " and " 4 " to " 6 ") is slightly different, chiefly owing to the difference in $\omega, \alpha$ ratio and reaction time. At $\omega=16.18$ and $\alpha<1$, the water droplet is smaller, and thus, irrespective of the reaction time, the diffusion of reactants lead to the formation of dense nanoparticle suspended in the water pool. On the other hand, upon increasing the $\omega$ to 20.23 and $\alpha>1$, the size of micelle increases, and thus, as the reaction occurs at the interface, hollow spheres form at lower reaction time owing to the auto-organization of the nanoparticles into a shell encompassing the water pool (droplet). However, as the reaction time increases, the inward growth of the nanostructure in the micelle leads to the formation of thick wall hollow-spheres, and finally dense nanoparticles of larger size. The dense nanoparticles (samples "1" to "3") and the hollow spheres (samples "4" to "6") self-assemble into cuboids in a concentric growth. The cuboids further self-assemble into 2D superlattices suggesting a faster growth in XY plane (horizontal) than in the z-axis direction (vertical). Owing to the fast growth in horizontal directions, the superlattices turned into truncated bi-pyramidal structures which eventually auto-organize themselves into almond-like super-structures. The auto-organization of the nanoparticles and then of the different structures like cuboids or truncated bi-pyramids is in fact controlled by the surfactants molecules on their surfaces and faces. As was observed previously ${ }^{29}$, the surfactant molecules on the surface of nanoparticles or on the facets of bigger structures act as anchorage sites by interdigitating their alkyl chain, and consequently, align the structures into ordered assemblies. This phenomenon is more evident from the SEM images of sample "5" (Figure 3-c \& d) and "6" (Figure 3-e \& f) in which the truncated bi-pyramidal superstructures are parallely aligned through the truncated facets. It is worth noting that the individual nanoparticles average size is not significantly related to the time parameter, but is rather is due to 
the water/oil ratio $(\alpha)$. Conversely, the time parameter drives the super-structure sizes. In conclusion, excepted slight differences about the sizes of the individual nanoparticles and that the sizes of super-structures depend of the reaction time, there is no crucial differences between the obtained self-assembled nanostructures.

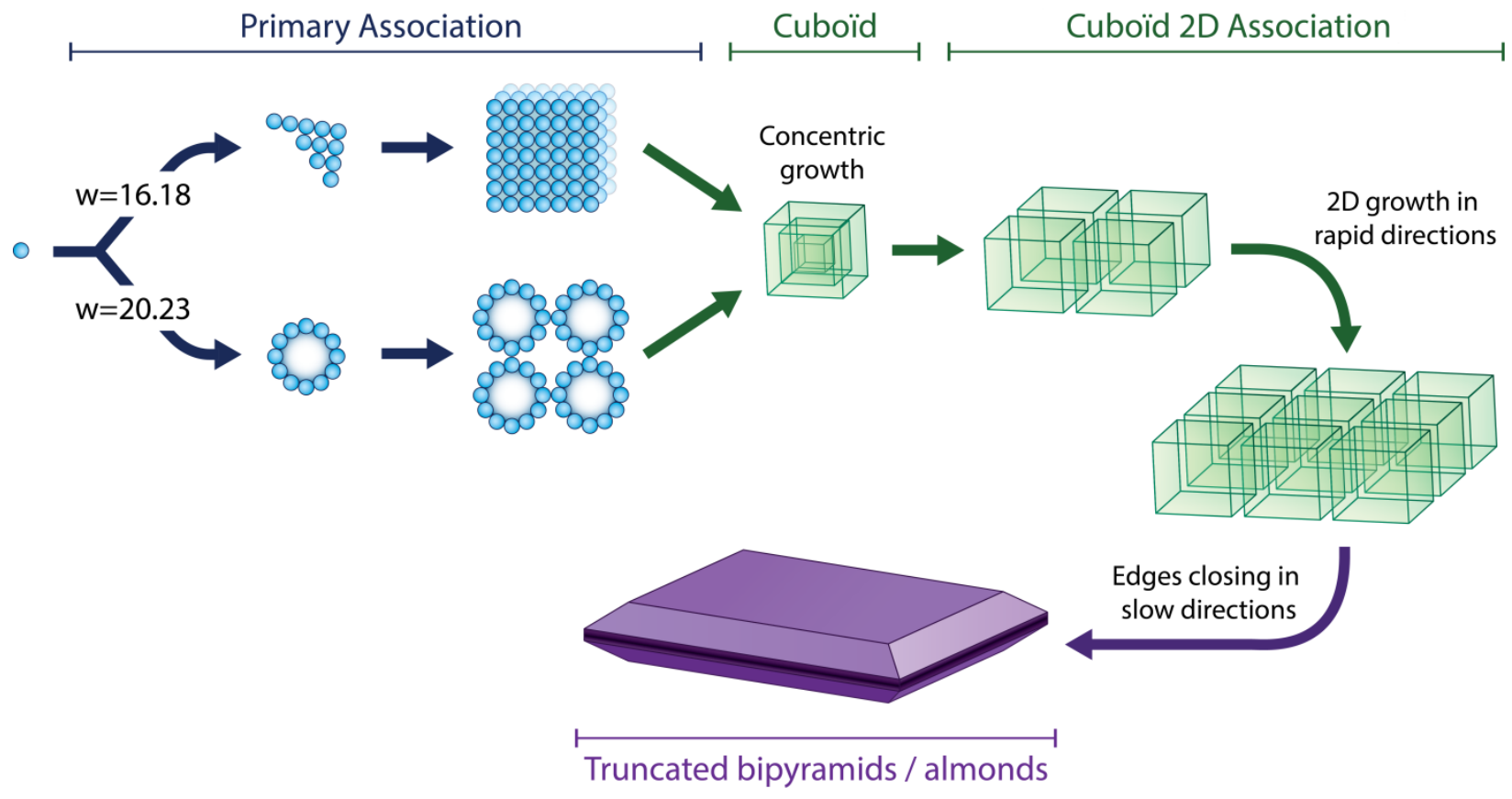

Figure 6. Schematic of cascade auto-organization process of nanoparticles/spheres into selfassembled super-structures

$\mathrm{NiF}_{2} \mathrm{NANOPARTICLES,THEIR}$ SELF-ASSEMBLIES AND THEIR PROPERTIES

\section{Conversion under $F_{2}$ :}

$\mathrm{NiF}_{2}$ nanostructures were prepared from $\mathrm{NiF}_{2} \cdot 4 \mathrm{H}_{2} \mathrm{O}$ nanoparticles self-assemblies by a deliberated two-step process. The carefully designed step by step heating process was followed 
in order to eliminate completely the crystallization water molecules from the lattice without damaging the self-assembled super structures. The simple vacuum drying is unable to deliver completely anhydrous crystalline $\mathrm{NiF}_{2}$.

The XRD pattern of a vacuum dried sample shows no clear peaks except a couple of broad humps (Figure 7-i). This indicates that the yellow powder ${ }^{52}$ obtained at the end of first step is amorphous. The amorphosity of powders is also evident from the Raman scattering spectrum which shows a broad peak around $400 \mathrm{~cm}^{-1}$ (Figure 7-iii). This indicates that upon removal of water, the lattice structure collapses. However, the removal of water is not complete, and this is evident from the IR spectrum which is comparable to that of precursor. As shown in Figure 7-ii, the FTIR spectrum gives broad peaks around $3220 \mathrm{~cm}^{-1}$ and $1612 \mathrm{~cm}^{-1}$ for $\mathrm{O}-\mathrm{H}$ stretching and bending vibrations, respectively, and at $679 \mathrm{~cm}^{-1}$ for $\mathrm{H}_{2} \mathrm{O}$ libration mode. This indicates that the dehydration of $\mathrm{NiF}_{2} \cdot 4 \mathrm{H}_{2} \mathrm{O}$ is incomplete at the end of first step. Nonetheless, TEM images show that the self-assemblies of nanoparticles are intact (supplementary Figure S5).
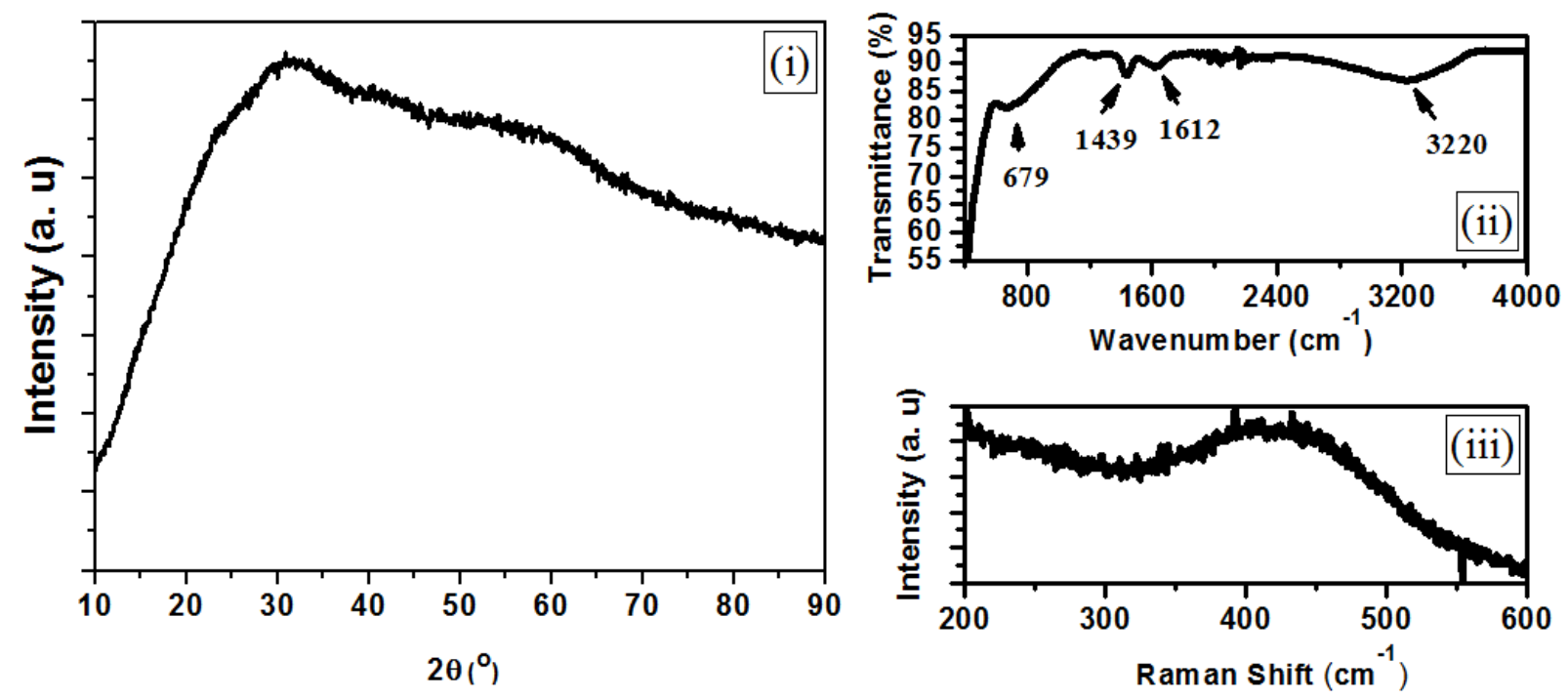
Figure 7. X-rays diffractogram (i), FTIR (ii) and Raman (iii) spectra of vacuum dehydrated $\mathrm{NiF}_{2} .4 \mathrm{H}_{2} \mathrm{O}$ nanoparticles (sample 5) at $100^{\circ} \mathrm{C}$ for 1 hour followed by at $250^{\circ} \mathrm{C}$ for 5 hours.

The resulting $\mathrm{NiF}_{2}$ nanoparticles obtained at the end of the second step are crystalline as evidenced by the diffractograms presented in Figure 8-a. The peaks of all the samples ("1-1" to "6-6") are indexed as $\mathrm{NiF}_{2}$ in tetragonal structure having $\mathrm{P} 42 / \mathrm{mnm}$ space group by matching with powder diffraction files (PDF) number [01-74-0917] and [00-24-0791] ${ }^{66}$. The $\mathrm{NiF}_{2}$ nanoparticles in all the samples consist of single phase as the XRD patterns show no peaks other than those of tetragonal $\mathrm{NiF}_{2}$. The average crystallite size was determined by Scherrer formula given in Eq. $1(\mathrm{~d}=0.94 \lambda / \beta \cos \theta)^{67}$. As shown in Table 2, the average crystallite size slightly increases as the time and the water contents of the reaction, employed for the synthesis of precursors, $\mathrm{NiF}_{2} .4 \mathrm{H}_{2} \mathrm{O}$, increases. It indicates that the crystallite size trend observed in hydrated $\mathrm{NiF}_{2} \cdot 4 \mathrm{H}_{2} \mathrm{O}$ nanoparticles is preserved after transformation to dehydrated $\mathrm{NiF}_{2}$ nanoparticles. However, by comparing the crystallite size data in Table 2 of the hydrated and dehydrated $\mathrm{NiF}_{2}$, respectively, the overall grain size is smaller in the dehydrated $\mathrm{NiF}_{2}$ than the hydrated $\mathrm{NiF}_{2} \cdot 4 \mathrm{H}_{2} \mathrm{O}$ nanoparticles. This could be attributed to the shrinkage of lattice after removal of water. 

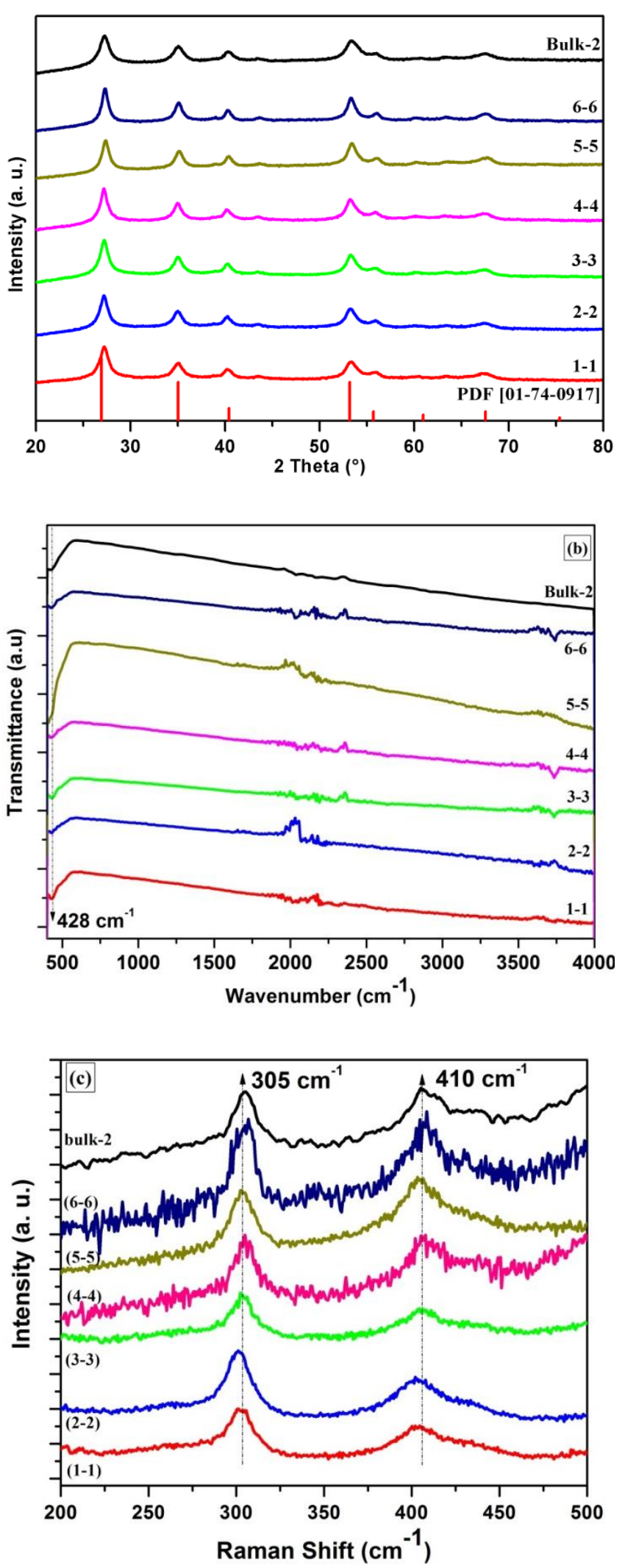
Figure 8. (a) Diffractograms, (b) FTIR, and (c) Raman spectra of $\mathrm{NiF}_{2}$ samples "1-1", "2-2", "“33", "4-4", "5-5" and "6-6" synthesized in a two-step process by the dehydration of $\mathrm{NiF}_{2} \cdot 4 \mathrm{H}_{2} \mathrm{O}$ nanoparticles samples “1”, “2”, “3”, “4”, “5” and "6” respectively, and bulk $\mathrm{NiF}_{2}$ (“Bulk-2”) prepared from bulk $\mathrm{NiF}_{2} \cdot 4 \mathrm{H}_{2} \mathrm{O}$ (“'Bulk-1”).

The typical mid FTIR spectra of samples "1-1" - "6-6" and bulk $\mathrm{NiF}_{2}$ ("Bulk-2") are presented in Figure 8-b. The IR spectra show that all the samples absorb moderately in the range of 450 $\mathrm{cm}^{-1}-410 \mathrm{~cm}^{-1}$. The single peak in this range corresponds to the $\mathrm{NiF}_{2}$ vibration ${ }^{68}$, and shifts to higher wave numbers due to nanostructuration in the spectra of $\mathrm{NiF}_{2}$ nanoparticles corresponding to the bulk. Apart from this peak, no other peak has been observed as shown in Figure 8-b. The complete absence of peaks other than the one mentioned indicates that the $\mathrm{H}_{2} \mathrm{O}$ molecules are completely removed under the given synthesis parameters.

Raman scattering spectra of $\mathrm{NiF}_{2}$ nanoparticles (samples "1-1" to "6-6") is in accordance with FTIR spectra, confirming efficient removal of $\mathrm{H}_{2} \mathrm{O}$ molecules. Raman spectra of $\mathrm{NiF}_{2}$ nanoparticles (samples "1-1" to "6-6") is presented in Figure 8-c which gives only two peaks in the range of $500 \mathrm{~cm}^{-1}-200 \mathrm{~cm}^{-1}$, and all the bands observed in the Raman spectra of precursors (Figure 1-c) due to $\mathrm{H}_{2} \mathrm{O}$ vibrations are absent. $\mathrm{NiF}_{2}$, a rutile structure compound having space group $\mathrm{D}_{4 \mathrm{~h}}^{14}$, has two raman active modes in the range of $500 \mathrm{~cm}^{-1}-200 \mathrm{~cm}^{-1}$ i.e., $\mathrm{A}_{1 \mathrm{~g}}$ and $\mathrm{E}_{\mathrm{g}}$ giving bands around $410 \mathrm{~cm}^{-1}$ and $305 \mathrm{~cm}^{-1}$, respectively ${ }^{63,69}$. Therefore, these peaks are assigned to the $\mathrm{NiF}_{2}$ vibrations due to $\mathrm{A}_{1 \mathrm{~g}}$ and $\mathrm{E}_{\mathrm{g}}$ modes. A slight red shift is observed with increase in crystallite size ${ }^{70}$. 
TEM images of the progenies (samples "1-1" to "6-6") are acquired to follow the preservation and/or retention of the self-assemblies of the precursors (samples " 1 " to "6") after dehydration of $\mathrm{NiF}_{2} \cdot 4 \mathrm{H}_{2} \mathrm{O}$ into $\mathrm{NiF}_{2}$. Figure 9 and Figure S6, TEM images of samples "1-1" to "6-6", show two types of self-assembled structures i.e., a larger almond-like and a comparatively smaller cuboids as were seen in the TEM images of the precursors (Figure 2 and 3). Furthermore, the 3D layer by layer construction of the self-assemblies of precursors is also observable in the TEM images of the derivatives (samples "1-1" to "6-6"). The nanoparticles are orderly arranged in horizontal layers which are subsequently packed/stacked giving cubic structures. The cuboids are further auto-organized giving truncated bi-pyramids and almond-like super-structures. The TEM images clarify the fact that the superlattices are the result of cascade auto-organization process. The sizes of the individual spherical-shaped nanoparticles observed on TEM images are bigger than the crystallites sizes determined by XRD analysis (Table 2). This suggests that, after thermal treatment under $F_{2}$, the obtained individual nanoparticles are polycrystalline. The moderate temperature $\left(350^{\circ} \mathrm{C}\right)$ could have caused a slight sintering between a few neighboring crystallites. 


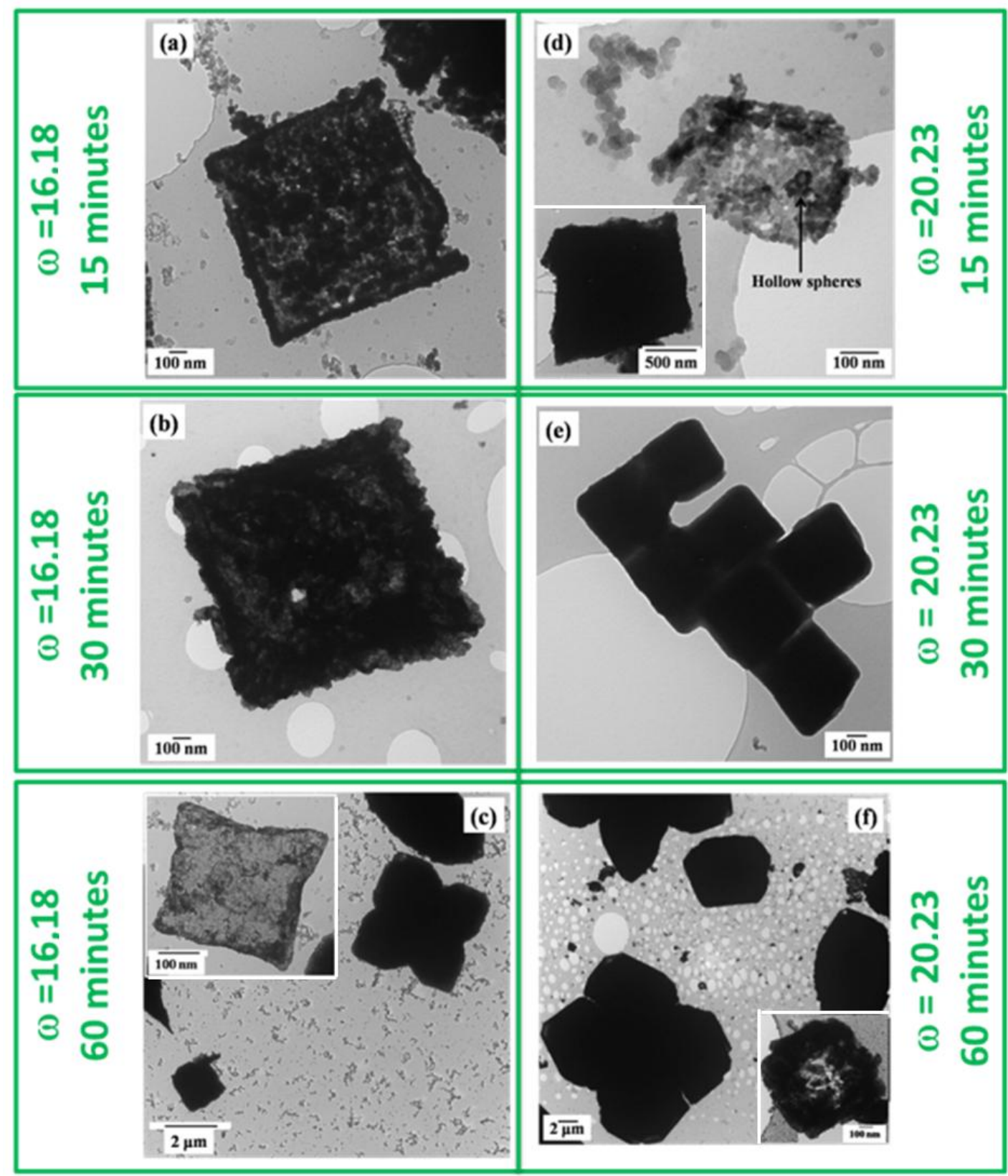

Figure 9. TEM images of samples "1-1" (a), "2-2" (b) , “3-3" (c), "4-4" (d) , "5-5" (e) and "66" (f) showing self-assembled nanoparticles giving cuboids and almond shaped super-structures; insets in (c) and (d) are shown the auto organized cubic structures in case of sample "3-3" and “4-4”, respectively. 
SEM images are acquired for the anhydrous $\mathrm{NiF}_{2}$ samples and presented in Figure 10. The basic self-assemblies i.e., almond shaped big structures and the truncated bi-pyramidal sub structures observed in the SEM images of precursors (Figure 2-c, d and 3-a, b) could be clearly seen in the SEM images of their progenies (Figure 10-a $-\mathrm{d}$ ). This is clear indication of the fact that the transformation process is secure and efficient enough to prepare $\mathrm{NiF}_{2}$ from $\mathrm{NiF}_{2} \cdot 4 \mathrm{H}_{2} \mathrm{O}$ while retaining the basic shapes of the self-organized architectures. Furthermore, the SEM images support the cascade auto-organization mechanism illustrated in Figure 6. High magnification SEM images of "2-2" and "4-4" in Figure 10-b and 10-d, respectively, show the impact of dehydration process upon the surface of the self-assemblies. As could be seen in SEM images, more clearly in the case of sample "2-2", the surfaces of self-assembled structures are marked with tiny holes. It is believed that the water molecules have escaped from the solid body through these holes. Besides the water molecules, these holes could have also been served as channels for escaping of volatile organic molecules like $\mathrm{CF}_{4}, \mathrm{C}_{2} \mathrm{~F}_{6}$ etc. which may be formed by the reaction of molecular $\mathrm{F}_{2}$ with the surfactant molecules left behind after washing. The presence of limited number of surfactant molecules is evident from the FTIR spectra of samples "1" - "6" (Figure 1b). In fact, the water and also the $\mathrm{CF}_{4}, \mathrm{C}_{2} \mathrm{~F}_{6}$ etc. molecules boiled off during heat treatment making small channels through the self-assembly body. This sort of porosity is also evident from the TEM images of $\mathrm{NiF}_{2}$ samples (Figure 9), and could help in enhancing the specific surface area of the materials and be favorable for electrochemical applications (anhydrous materials will be tested as conversion based electrode material in secondary batteries). 

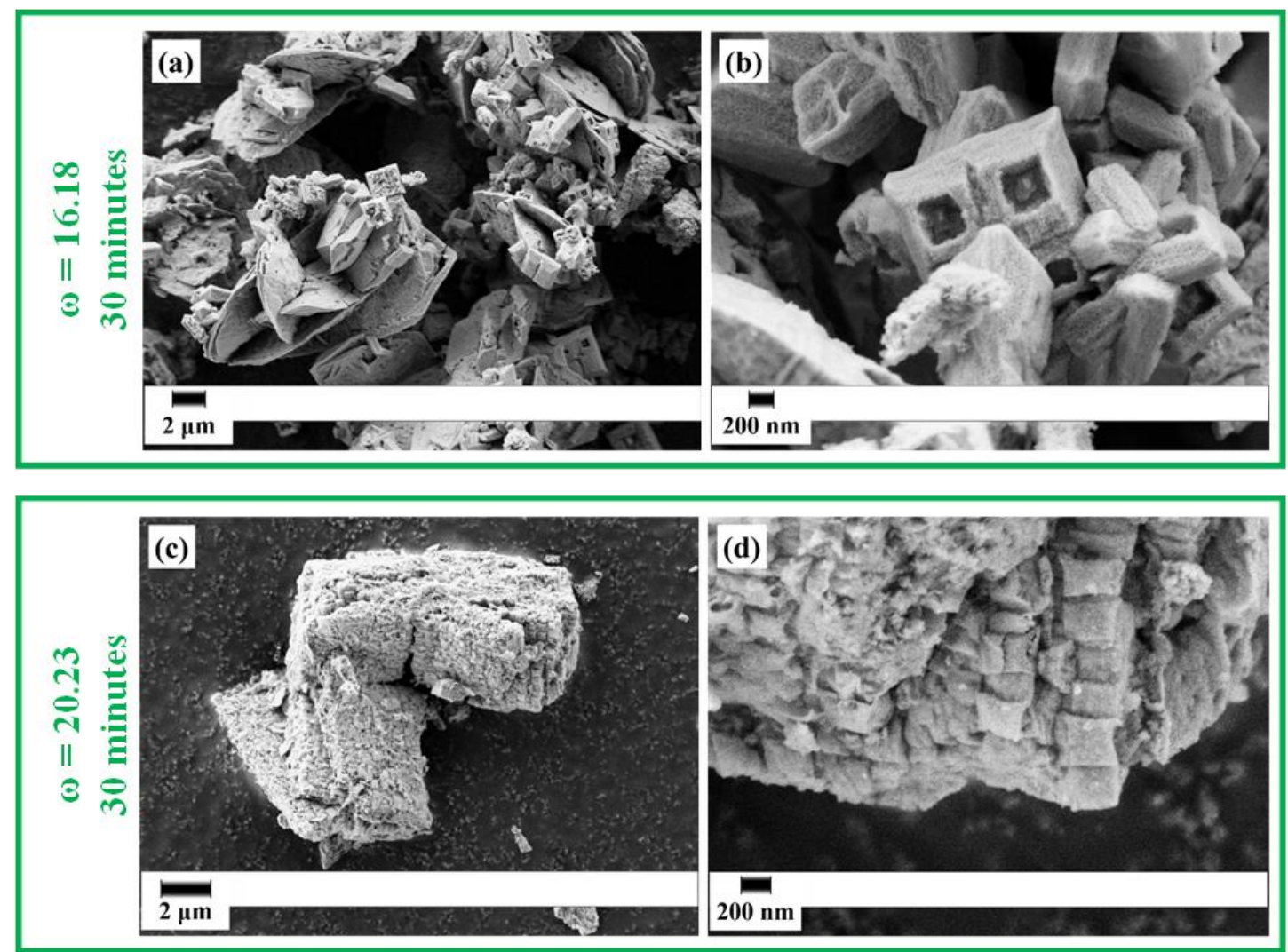

Figure 10. SEM images of dehydrated $\mathrm{NiF}_{2}$ samples "2-2" (a, b), and "4-4" (c, d) prepared from the $\mathrm{NiF}_{2} \cdot 4 \mathrm{H}_{2} \mathrm{O}$ samples " 2 " and " 4 ", respectively, which were heated under vacuum at $250^{\circ} \mathrm{C}$ for 5 hours followed by heating under dynamic fluorine at $350^{\circ} \mathrm{C}$ for 5 hours.

\section{Surface characterizations and properties:}

The $\mathrm{N}_{2}$ adsorption-desorption isotherms at $77 \mathrm{~K}$ of the anhydrous nano-structurated $\mathrm{NiF}_{2}$ samples ("1-1" to "6-6") were measured employing Brunauer-Emmett-Teller (BET) method for obtaining the specific surface area and compared with bulk material ("Bulk-2"). The pertinent data are summarized in Table 3 and the $\mathrm{N}_{2}$ sorption isotherms are presented in supplementary materials (Figure S7). The shape of adsorption-desorption isotherms for all the samples ("1-1" to "6-6") corresponds to the type $\mathrm{IV}^{71}$. From the type of isotherms and the pore size distributions (insets in 
supplementary Figure S7), it is evident that materials of all the samples are mesoporous ${ }^{71}$. The developed porosity could be mainly ascribed to the interparticle spaces, and in good accordance with TEM and SEM images (Figure 9 and 10, respectively). The BET specific surface areas, and BJH (Barret-Joyner-Halenda) pore volumes and pore diameters of all the samples are comparable and are more than $60 \%$ higher than the values obtained for the bulk material. This could be attributed to the auto-organization of nanoparticles into super-structures. However, the sample "2-2" has shown maximum specific surface area and pore volumes in comparison to their analogues about $50 \mathrm{~m}^{2} / \mathrm{g}$. This could be due to a larger number of tiny channels produced during the dehydration in case of sample "2-2" compared to their analogues and to the concomitant collapsing of the superior faces. The production of tiny holes is evident from the SEM image of sample "2-2" (Figure 10-a, b). These holes could act as diffusion channels for $\mathrm{N}_{2}$ molecules into the body of the super-structures. The $\mathrm{N}_{2}$ sorption isotherms profiles of the nanostructured materials also highlight the presence of mesopores with a large hysteresis between the sorption and desorption curves at high relative pressure compared to the "bulk-2" sample. That could be ascribed to the channels between the nanoparticles composing the super-structures, in good agreement with the pores volumes values obtained by the BJH method. These results show that the microemulsion synthesis allows obtaining nanomaterials with SSA about $30 \mathrm{~m}^{2} / \mathrm{g}$ (average value), higher more than $60 \%$ the SSA of sample obtained by a direct synthesis in aqueous HF $\left(\sim 18 \mathrm{~m}^{2} / \mathrm{g}\right)$. This value could be increased and reaches $\sim 50 \mathrm{~m}^{2} / \mathrm{g}$, as shown in the case of the sample "2-2". Thanks to this synthesis method, self-assembled nano- $\mathrm{NiF}_{2}$ samples offer an interesting surface of interaction with a surrounding medium like an electrolyte. Indeed, these interesting SSA values could be an advantage for electrochemical application, especially for the lithium diffusion. 
Table 3. BET specific surfaces areas and BJH pores volumes of samples "1-1”, "2-2”, "3-3", “44", "5-5" and "6-6" prepared by the dehydration of $\mathrm{NiF}_{2} \cdot 4 \mathrm{H}_{2} \mathrm{O}$ nanoparticles at $250^{\circ} \mathrm{C}$ and $350^{\circ} \mathrm{C}$ under vacuum and dynamic fluorination, respectively. Comparison with $\mathrm{NiF}_{2}$ bulk sample obtained in aqueous HF and treated in similar conditions.

\begin{tabular}{ccc}
\hline Sample & $\begin{array}{c}\text { Surface Area }\left(\mathrm{m}^{2} / \mathbf{g}\right) \\
(\text { BET })\end{array}$ & $\begin{array}{c}\text { Pore Vol. }\left(\mathrm{cm}^{3} / \mathbf{g}\right) \\
\text { BJH Desorption }\end{array}$ \\
\hline "1-1" & 31.7 & 0.079 \\
“2-2" & 51.0 & 0.102 \\
“3-3" & 33.2 & 0.076 \\
\hline "4-4" & 24.8 & 0.050 \\
“5-5" & 29.1 & 0.076 \\
“6-6" & 15.4 & 0.040 \\
\hline "NiF Bulk" & 18.6 & 0.013 \\
\hline
\end{tabular}

Being representative of the different samples resulting from the micro-emulsion syntheses, as well as about the organization and the morphology, than about the specific surface area, the sample "3-3" was chosen for the study of the electrochemical activity of self-assembled nano$\mathrm{NiF}_{2}$ materials.

The Li storage capacities and cycle performances of self-assembled nano-NiF 2 (sample "3-3") were investigated by discharge/charge galvanostatic measurements and compared with $\mathrm{NiF}_{2}$ bulk (bulk-2). Figures $11-\mathrm{a} / \mathrm{b}$ show the first and second discharge and charge curves of $\mathrm{NiF}_{2} / \mathrm{Li}$ cells cycled between $1 \mathrm{~V}$ and $4.3 \mathrm{~V}$ at a constant current density of $10 \mathrm{~mA} / \mathrm{g}$ for the chosen nanostructured material (“3-3") compared to the bulk material ones ("Bulk 2"). The voltage profiles exhibit its electrochemical activity with a flat voltage plateau at $1.65 \mathrm{~V}$ for the sample "3-3" in the first discharging process (for instance the same plateau is at $1.55 \mathrm{~V}$ for the sample 
"1-1" as seen in Figure S8. This values is higher than the value obtained for bulk material at $1.45 \mathrm{~V}$, meaning a lower polarization and a better lithium diffusion process in nanomaterial by comparison of bulk material. This voltage plateau, as the general voltage profile, is equivalent to the one described by Lee et al. for pristine and NiO-doped nickel fluoride and by Teng et al. for nanostructured $\mathrm{NiF}_{2}{ }^{46,72}$. The first discharge capacity of nano- $\mathrm{NiF}_{2}$ is about $650 \mathrm{mAh} / \mathrm{g}$ and is higher than the theoretical value of $554 \mathrm{mAh} / \mathrm{g}$. This is explained by a concomitant redox mechanism of $\mathrm{NiF}_{2}$ and the formation of a Solid Electrolyte Interface (SEI) ${ }^{46}$. The irreversible capacity leading to SEI is directly proportional to the SSA. As the nanostructured materials "1-1" and "3-3" have about the same SSA, their SEI are attempted to be the same leading to the same discharge capacity (see Figure S8 for sample "1-1"). In parallel, since the SSA of bulk $\mathrm{NiF}_{2}$ is lower than the one of the nanostructured compounds, only a fewer irreversible capacity can contribute to the first reduction capacity. Moreover, the first reduction capacity of the bulk material is lower than the theoretical value, so lithium diffusion process may be limited the access to the overall active material. A better diffusion of the lithium ions in the more opened structures of the self-organized $\mathrm{NiF}_{2}$ nanoparticles compared with the bulk compound (see Figure 11-b) can explain the higher value of the second reduction capacity for " $3-3$ " sample than $\mathrm{NiF}_{2}$ bulk.

In the literature, two different mechanisms have been proposed concerning the electrochemical activity of $\mathrm{NiF}_{2}$. In their studies, Dae Hoe Lee et al. have described a conversion mechanism supported by XAS and XRD measurements ${ }^{46,73}$. According the authors, the first cycle profile appears as different as the second one because of a conversion mechanism of $\mathrm{NiF}_{2}$ into $\mathrm{Ni}$ during which the $\mathrm{NiF}_{2}$ particles are electrochemically ground and reduced into little particles of nickel. Then the following oxidation gives heterogeneous $\mathrm{NiF}_{2}$ particles with different electrochemical 
potentials. So no flatter plateau of $\mathrm{NiF}_{2}$ can be obtained during the second reduction process. In another side, a study of Zhang et al. ${ }^{7}$ made on $\mathrm{NiF}_{2}$ nanoparticles about of $20-30 \mathrm{~nm}$ in size deposited by pulse laser deposition shows good electrochemical performances for $\mathrm{NiF}_{2}$ used as cathode in lithium batteries (more than 40 cycles and a delivered capacity higher than 400 $\mathrm{mAh} / \mathrm{g}$ between $3.5 \mathrm{~V}$ and $0 \mathrm{~V}$ ), because of the stabilization of $\mathrm{Li}_{2} \mathrm{NiF}_{4}$ as an intermediate during the reversible electrochemical reaction of $\mathrm{NiF}_{2}$ with $\mathrm{Li}$. The galvanostatic curves of our samples (nanostructured and bulk) are very similar with those presented in the studies of Lee et al., and are dissimilar to those reported by Zhang et al. This is the case on the plateau values during the first discharge or on next cycles. To confirm the electrochemical mechanism of our $\mathrm{NiF}_{2}$ samples (bulk and nanostructured " $3-3$ " sample), the changes of the oxidation state of nickel have been followed by XAS thanks several galvanostatic measurements with various cutoff voltage at 1.5 and 1.0V in reduction and 1.5, 3.2, 4.0 and 4.3V over the first and second cycles (Figure 11-c/d). In the case of the bulk material, the Ni K-edge energy varies between 8344 and $8339.6 \mathrm{eV}$ during the reduction, whereas in the case of sample " $3-3$ " a minimum of $8338 \mathrm{eV}$ for the same edge is obtained. This last minimum is narrower to the attempted value of metallic nickel at $8333 \mathrm{eV}^{73}$. It demonstrates that more metallic nickel amount is obtained for nanomaterial than for bulk sample. This result shows that the electrochemical mechanisms of our bulk and nanostructured $\mathrm{NiF}_{2}$ are quite the same, that is to say a conversion process to metallic nickel and that demonstrating a better efficiency of formation of metallic nickel for the nanostructured material than the bulk one ${ }^{73}$. Moreover, it demonstrates also that no reaction between $\mathrm{Ni}$ and LiF occurred to stabilize nickel into $\mathrm{Li}_{2} \mathrm{NiF}_{4}$ as at the end of oxidation ${ }^{74}$, the recovering of starting spectra is obtained in both cases. Indeed, the XANES region is mostly determined by valence, the

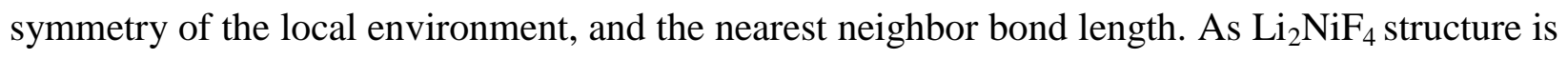


$\mathrm{Fd} 3 \mathrm{~m}$ and the one of $\mathrm{NiF}_{2}$ is $\mathrm{P}_{2} / \mathrm{mnm}$, one can conclude that the formation of $\mathrm{Li}_{2} \mathrm{NiF}_{4}$ is avoided. So, our synthesized (nano)-particles do not favor the formation of the $\mathrm{Li}_{2} \mathrm{NiF}_{4}$ phase and exhibit an electrochemical behavior very similar with the conversion mechanism proposed by Lee et al. with a rapid decrease of the capacity after only two cycles due to the SEI formation during the first cycle. Nevertheless, the values of capacities reached by nanostructured $\mathrm{NiF}_{2}$ are higher than those relatives to the bulk compound. These results give evidences that $\mathrm{NiF}_{2}$ organization into self-assembled nanostructures appears to be more favorable than dense and bulk structures for its electrochemical activity.

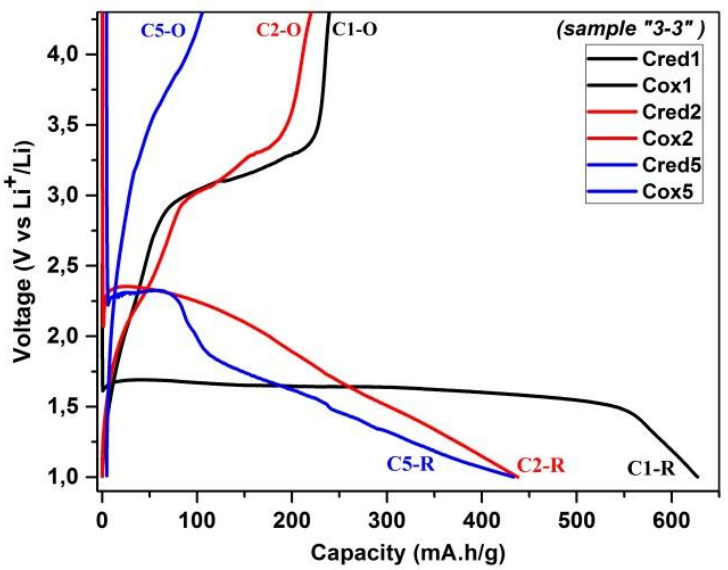

(a)

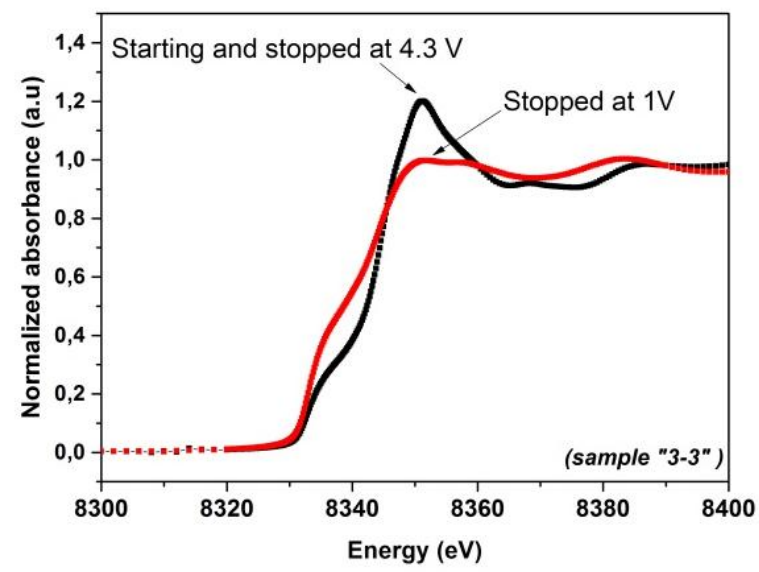

(c)

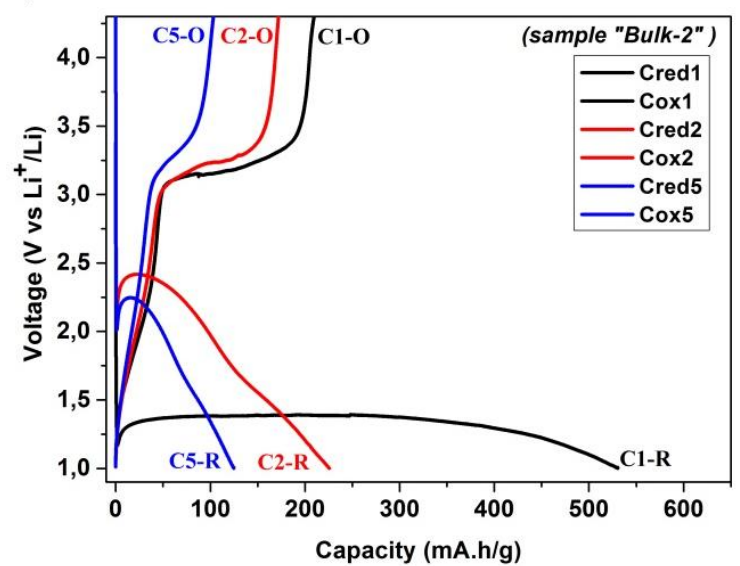

(b)

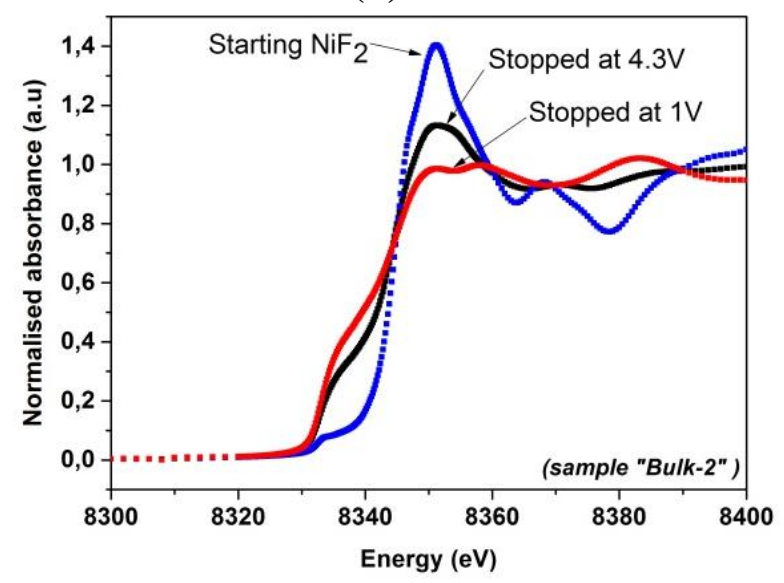

(d) 
Figure 11. First, second and fifth galvanostatic cycles of half-cells using as cathode material sample "3-3" (a) compared to those of bulk material (sample "bulk-2") (b). Oxidation and reduction process are labeled "Cox" and "Cred" respectively. XANES spectra of the nanostructured "3-3" (c) and bulk (sample "bulk-2") (d) $\mathrm{NiF}_{2}$ electrode materials before electrochemical measurements or after 1 full cycle and 1 reduction, stopped at $4.3 \mathrm{~V}$ or $1 \mathrm{~V}$.

\section{Magnetic characterizations:}

The magnetic properties of the samples "bulk-1" and "bulk-2", and of nanoparticles samples "1", "6", "1-1" and "6-6" were investigated under a 5000 Oe dc magnetic field in zero-field-cooled (ZFC) mode in the temperature range $1.8-300 \mathrm{~K}$. The molar magnetic susceptibilities curves as a function of temperature for samples "bulk-1", "1" and "6" are given in Figure 12-a, and for samples "bulk-2", "1-1" and "6-6" in Figure 12-b. The inverse of the susceptibility curves can be fitted by the Curie-Weiss law in the high temperature region (above $150 \mathrm{~K}$ ) (shown in Fig S9 (af)), which provides Curie constants around $1.36 \mathrm{emu} \cdot \mathrm{K} \cdot \mathrm{mol}^{-1}$ for the hydrated compounds ("bulk-1", sample "1" and sample "6") and slightly larger, around $1.41 \mathrm{emu} \cdot \mathrm{K} \cdot \mathrm{mol}^{-1}$, for the dehydrated compounds ("bulk-2", sample "1-1" and sample "6-6"). These values of the Curie constant are well consistent with the expected value for the $\mathrm{Ni}$ (II) ion $\left(\sim 1.3 \mathrm{emu} . \mathrm{K} \cdot \mathrm{mol}^{-1}\right)$ in octahedral geometry and the value about $1.36 \mathrm{emu} . \mathrm{K} \cdot \mathrm{mol}^{-1}$ found for $\mathrm{NiF}_{2}$ by Cooke et al. ${ }^{75}$. The Weiss temperatures are negative (around $-8.7 \mathrm{~K}$ for the hydrated samples, and around $-130 \mathrm{~K}$ for the dehydrated samples), which indicates the occurrence of dominant antiferromagnetic interactions, much larger in the case of the dehydrated samples. The ZFC curves for samples "bulk-1", "1" and "6" show a single and relatively sharp peak around $3.8 \mathrm{~K}$ which indicates the occurrence of antiferromagnetic ordering. It is worth noticing that to the best of our knowledge, 
it is the first time the magnetic behavior of $\mathrm{NiF}_{2} \cdot 4 \mathrm{H}_{2} \mathrm{O}$ is reported. No influence of the size reduction and self-assembly can be noticed.

The ZCF curves of anhydrous $\mathrm{NiF}_{2}$ ("bulk-2", sample "1-1" and sample "2-2") show two peaks at $\sim 4 \mathrm{~K}$ and $\sim 74 \mathrm{~K}$. The peak at $74 \mathrm{~K}$ corresponds to the already reported Néel temperature of $\mathrm{NiF}_{2}{ }^{75-76}$. There again, no change of the magnetic properties of $\mathrm{NiF}_{2}$ nanoparticles compared to their bulk counterpart can be noticed, most probably because the size of the obtained nanoparticles is still too large to detect any significant size reduction effect. Indeed, the modeling work of Lang et al. ${ }^{77}$ shows that in the case of $\mathrm{NiF}_{2}$, the effects of reducing the Néel temperature with the particle size become significant only for nanoparticle sizes smaller than $10 \mathrm{~nm}$. In our case, the smallest $\mathrm{NiF}_{2}$ particles have sizes of the order of $24 \mathrm{~nm}$ and monocrystalline domains of $13 \mathrm{~nm}$. Again, no noticeable influence of self-assembly is observed. The emergence of a second peak around $4 \mathrm{~K}$ is rather surprising and likely corresponds to the presence of a small quantity of $\mathrm{NiF}_{2} \cdot 4 \mathrm{H}_{2} \mathrm{O}$ that could be probably due to a slight hydration of the compounds before measurement 

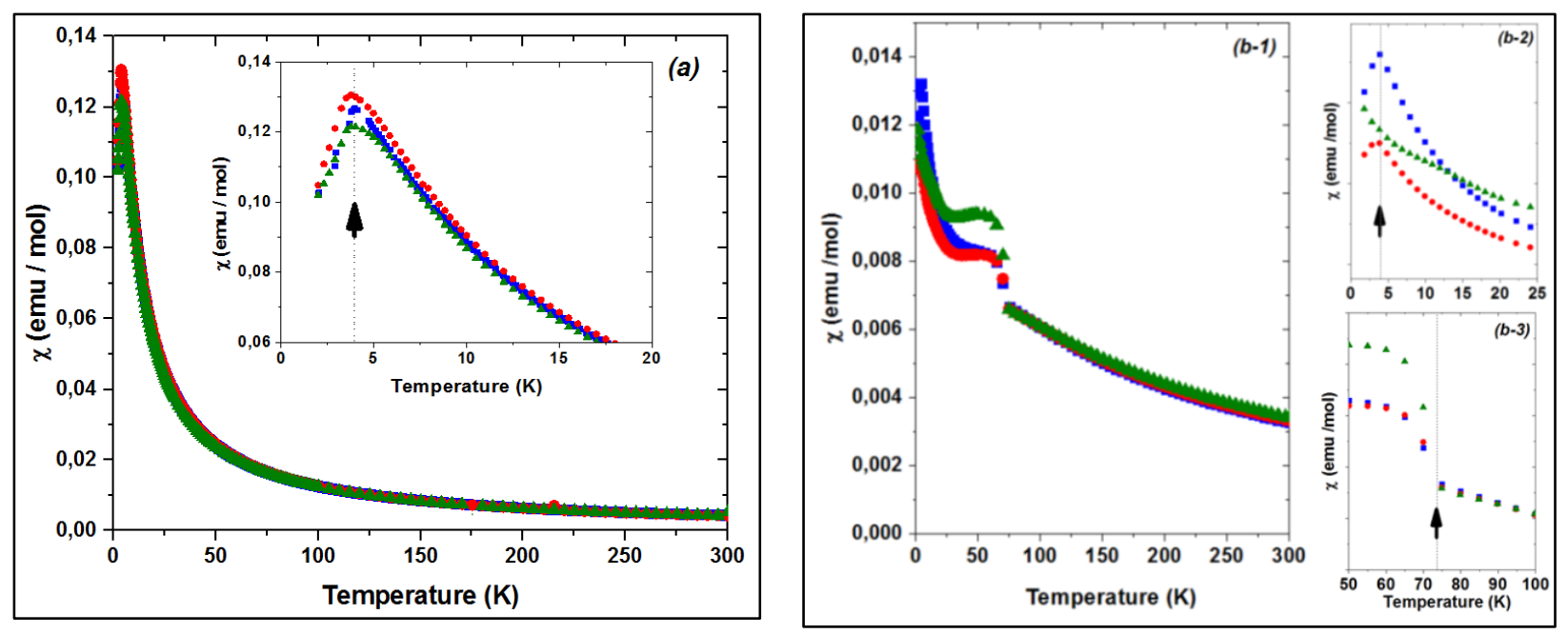

Figure 12. (a) $\chi=\mathrm{f}(\mathrm{T})$ curves for "bulk-1" (blue), sample " 1 " (red) and sample " 6 " (green), and (b) "bulk-2" (blue), sample "1-1" (red) and sample "6-6" (green) under a 5000 Oe dc magnetic field (zfc mode). Insert in figure (a) is a zoom around $4 \mathrm{~K}$ for hydrated compounds, while figures (b-2) and (b-3) are zooms around $4 \mathrm{~K}$ and $74 \mathrm{~K}$ respectively for anhydrous compounds.

\section{CONCLUSION}

Obtaining self-assembled nanoparticles of anhydrous metal fluoride is a real challenge. Indeed, most of fluorides of transition metal present hydrated forms, but in the same time nanostructuration with self-assembly is generally obtained in aqueous media. In this paper, microemulsion method has been used for the first time to make self-assembled nanoparticles of $\mathrm{NiF}_{2} .4 \mathrm{H}_{2} \mathrm{O}$ and the obtained compounds have been successfully converted into anhydrous $\mathrm{NiF}_{2}$ while preserving self-assemblies thanks to controlled gas/solid fluorination. 
The influence of the synthesis parameters of the water-in-oil microemulsion method, such as time or water/2-octanol ratio has been studied. The control of these parameters does not change strongly the size and the shape of the individual nanoparticles, even a small increase as a result of increasing the reaction time and the water to octanol ratio of the microemulsions. The morphological studies revealed an assembly mechanism made by a cascade of auto-organization process from the primary auto-organization of the individual nanoparticles into layers which packed together to give tiny cubes to their self-assembly giving truncated bipyramids. The preferential plane growth mechanism for the successive assemblies leads the formation of large almond-like super-structures. Unlike the formation of the individual nanoparticles, the synthesis parameters have a significant influence on their self-assembly. The water/2-octanol ratio $(\alpha)$ drives the primary auto-organization of the individual nanoparticles while the super-structures size depends on the reaction time. The controlled post-treatment of fluorination under molecular fluorine allows transforming hydrated nickel fluoride nanoparticles into anhydrous particles without destruction of the self-assembled structures. The self-assembled structure and the water released by fluorination lead to noticeable surface areas which promote better $\mathrm{Li}^{+}$diffusion during charge/discharge of the LIBs compared with bulk $\mathrm{NiF}_{2}$. The electrochemical activity of the self-assembled materials has been investigated and compared with bulk sample, it clearly shows the importance of the nano-structuration on the SEI formation along the redox process of $\mathrm{NiF}_{2}$. The electrochemical conversion mechanism is confirmed XAS measurements and the discharges capacities are in good agreement with values presented in the literature. Finally, the magnetic characterizations of nanostructured hydrated (for the first time) and anhydrous $\mathrm{NiF}_{2}$ show the same behaviors than the bulk materials, without any noticeable size-reduction and selfassembly effect. 
This paper shows that our combined synthesis method (microemulsion + fluorination) has high potential for making self-assembled nanosized anhydrous nickel fluoride. It appears to be very promising for the controlled synthesis of anhydrous functional fluorides with the mutual benefits of nanostructuration, self-assembly and water-free compounds. This study opens way for future works concentrated upon the electrochemical studies of the self-assembled materials and the optimization the charge/discharge process.

\section{SUPPORTING INFORMATION}

Synthesis of $\mathrm{NiF}_{2} \cdot 4 \mathrm{H}_{2} \mathrm{O}$ at low water to oil ratio $(\alpha \sim 0.7)$. Synthesis of $\mathrm{NiF}_{2} \cdot 4 \mathrm{H}_{2} \mathrm{O}$ AND NiF (Synthesis parameters, TGA, fluorination and TEM pictures). Isotherms and the pore size distributions of $\mathrm{NiF}_{2}$ samples. First Galvanostatic cycle of half cell using as cathode material sample "1-1". Magnetic characterizations and properties of samples "1", "6", "1-1" "6-6"AND "bulk-1" and "bulk-2".

\section{ACKNOWLEDGEMENTS}

We sincerely acknowledge Higher Education Commission (HEC) of Pakistan, Campus France and Embassy of France in Pakistan for granting post-doctoral fellowship to one of the authors (Dr. Hameed Ullah) under the program "2014 HEC and French Embassy Split PhD and PostDoc Scholarship Programme”. We thank Mr. Fabien Veillon and Dr. Alain Pautrat (CRISMAT, Caen), for their help with some magnetic measurements. The authors thank the platform Centre Imagerie Cellulaire Sante (Clermont Auvergne University), most notably Christelle Blavignac, for her technical assistance in TEM analysis. We thank all people of ICCF who help on this study: Mr. Joel Cellier (ICCF) and Rodolphe Thirouard (ICCF) for XRD and TGA/DSC 
analysis, respectively; Dr. Lea Doubtsof (ICCF) and Yin Zhang are thanked for electrochemical tests; Pr. Mohammad Sarakha (ICCF) for his help in DRS measurements and to Dr. Diane Delbegue (ICCF), Dr. Fabrice Leroux (ICCF) and Dr. Stephanie Belin (Synchrotron SOLEIL Rock Line) for helping us on XAS measurements and analyses. Our sincere thanks go to Synchrotron SOLEIL for the beam time allowed on the Rock line.

\section{REFERENCES}

1. Goldberger, J.; He, R.; Zhang, Y.; Lee, S.; Yan, H.; Choi, H.-J.; Yang, P., Single-crystal gallium nitride nanotubes. Nature 2003, 422 (6932), 599.

2. Perepichka, D. F.; Rosei, F., Metal nanoparticles: From "artificial atoms" to "artificial molecules". Angew. Chem., Int. Ed. 2007, 46 (32), 6006-6008.

3. Liu, J.; Xue, D., Hollow nanostructured anode materials for Li-ion batteries. Nanoscale. Res. Lett. 2010, 5 (10), 1525.

4. Liu, J.; Xia, H.; Xue, D.; Lu, L., Double-shelled nanocapsules of $\mathrm{V}_{2} \mathrm{O}_{5}$-based composites as high-performance anode and cathode materials for Li ion batteries. J. Am. Chem. Soc. 2009, 131 (34), 12086-12087.

5. Liu, J.; Liu, F.; Gao, K.; Wu, J.; Xue, D., Recent developments in the chemical synthesis of inorganic porous capsules. J. Mater. Chem. 2009, 19 (34), 6073-6084.

6. Ullah, H.; Khatoon, A.; Akhtar, Z., Synthesis and photocatalytic study of $\mathrm{SnO}_{2} / \mathrm{Zn}_{2} \mathrm{SnO}_{4}$ nanocomposite prepared by sol-gel method using single source molecular precursor. Mater. Res. Express 2014, 1 (4), 045001.

7. Zhang, H.; Zhou, Y.-N.; Sun, Q.; Fu, Z.-W., Nanostructured nickel fluoride thin film as a new Li storage material. Solid. State Sci. 2008, 10 (9), 1166-1172. 
8. Fedorov, P. P.; Luginina, A. A.; Kuznetsov, S. V.; Osiko, V. V., Nanofluorides. J. Fluorine Chem. 2011, 132 (12), 1012-1039.

9. Tarascon, J.-M.; Armand, M., Issues and challenges facing rechargeable lithium batteries. In Materials for Sustainable Energy: A Collection of Peer-Reviewed Research and Review Articles from Nature Publishing Group, World Scientific: 2011; pp 171-179.

10. Bruce, P. G.; Scrosati, B.; Tarascon, J. M., Nanomaterials for rechargeable lithium batteries. Angew. Chem., Int. Ed. 2008, 47 (16), 2930-2946.

11. Armand, M.; Tarascon, J.-M., Building better batteries. Nature 2008, 451 (7179), 652.

12. Kuzyk, A.; Schreiber, R.; Fan, Z.; Pardatscher, G.; Roller, E.-M.; Högele, A.; Simmel, F. C.; Govorov, A. O.; Liedl, T., DNA-based self-assembly of chiral plasmonic nanostructures with tailored optical response. Nature 2012, 483 (7389), 311.

13. Henry, E.; Dif, A.; Schmutz, M.; Legoff, L.; Amblard, F.; Marchi-Artzner, V.; Artzner, F., Crystallization of fluorescent quantum dots within a three-dimensional bio-organic template of actin filaments and lipid membranes. Nano Lett. 2011, 11 (12), 5443-5448.

14. Zhang, Y.; Lu, F.; Yager, K. G.; Van Der Lelie, D.; Gang, O., A general strategy for the DNA-mediated self-assembly of functional nanoparticles into heterogeneous systems. Nat. Nanotechnol. 2013, 8 (11), 865.

15. Hoffelner, D.; Kundt, M.; Schmidt, A. M.; Kentzinger, E.; Bender, P.; Disch, S., Directing the orientational alignment of anisotropic magnetic nanoparticles using dynamic magnetic fields. Faraday Discuss. 2015, 181, 449-461.

16. Alivisatos, A. P., Semiconductor clusters, nanocrystals, and quantum dots. Science 1996, 271 (5251), 933-937. 
17. Yin, J.; Wang, Z., In situ structural evolution of self-assembled oxide nanocrystals. $J$. Phys. Chem. B 1997, 101 (44), 8979-8983.

18. Barringer, E. A.; Bowen, H. K., Formation, packing, and sintering of monodisperse $\mathrm{TiO}_{2}$ powders. J. Am. Ceram. Soc. 1982, 65 (12), C199-C201.

19. Kitching, H.; Shiers, M. J.; Kenyon, A. J.; Parkin, I. P., Self-assembly of metallic nanoparticles into one dimensional arrays. J. Mater. Chem. A 2013, 1 (24), 6985-6999.

20. Mohl, M.; Dombovari, A.; Vajtai, R.; Ajayan, P. M.; Kordas, K., Self-assembled large scale metal alloy grid patterns as flexible transparent conductive layers. Sci. Rep. 2015, 5, 13710. 21. Siffalovic, P.; Majkova, E.; Chitu, L.; Jergel, M.; Luby, S.; Satka, A.; Roth, S., Selfassembly of iron oxide nanoparticles studied by time-resolved grazing-incidence small-angle xray scattering. Phys. Rev. B 2007, 76 (19), 195432.

22. Tsuruoka, T.; Kawasaki, H.; Nawafune, H.; Akamatsu, K., Controlled self-assembly of metal-organic frameworks on metal nanoparticles for efficient synthesis of hybrid nanostructures. ACS Appl. Mater. Inter. 2011, 3 (10), 3788-3791.

23. Peng, X.; Manna, L.; Yang, W.; Wickham, J.; Scher, E.; Kadavanich, A.; Alivisatos, A. P., Shape control of CdSe nanocrystals. Nature 2000, 404 (6773), 59.

24. Whitesides, G. M.; Grzybowski, B., Self-assembly at all scales. Science 2002, 295 (5564), 2418-2421.

25. Rycenga, M.; McLellan, J. M.; Xia, Y., Controlling the assembly of silver nanocubes through selective functionalization of their faces. Adv. Mater. 2008, 20 (12), 2416-2420.

26. Lu, F.; Yager, K. G.; Zhang, Y.; Xin, H.; Gang, O., Superlattices assembled through shape-induced directional binding. Nat. Commun. 2015, 6, 6912. 
27. Talapin, D. V.; Shevchenko, E. V.; Murray, C. B.; Titov, A. V.; Kral, P., Dipole- dipole interactions in nanoparticle superlattices. Nano Lett. 2007, 7 (5), 1213-1219.

28. Burnside, S. D.; Shklover, V.; Barbé, C.; Comte, P.; Arendse, F.; Brooks, K.; Grätzel, M., Self-organization of $\mathrm{TiO}_{2}$ nanoparticles in thin films. Chem. Mater. 1998, 10 (9), 2419-2425.

29. Li, M.; Schnablegger, H.; Mann, S., Coupled synthesis and self-assembly of nanoparticles to give structures with controlled organization. Nature 1999, 402 (6760), 393.

30. Kipouros, G.; Flengas, S., Electrorefining of zirconium metal in alkali chloride and alkali fluoride fused electrolytes. J. Electrochem. Soc. 1985, 132 (5), 1087-1098.

31. Herbst, R.; McCandless, F., Improved donors for the separation of the boron isotopes by gas-liquid exchange reactions. Sep. Sci. Technol. 1994, 29 (10), 1293-1310.

32. Ohishi, Y.; Mitachi, S.; Kanamori, T.; Manabe, T., Optical absorption of 3d transition metal and rare earth elements in zirconium fluoride glasses. Phys. Chem. Glasses. 1983, 24 (5), $135-140$.

33. Fergus, J. W., The application of solid fluoride electrolytes in chemical sensors. Sensor Actuat. B-Chem. 1997, 42 (2), 119-130.

34. Delcet, J.; Heus, R.; Egan, J., Electronic conductivity in solid $\mathrm{CaF}_{2}$ at high temperature. J. Electrochem. Soc. 1978, 125 (5), 755-758.

35. Zhang, Z.; Yu, L.; Liu, W.; Xue, Q., The effect of $\mathrm{LaF}_{3}$ nanocluster modified with succinimide on the lubricating performance of liquid paraffin for steel-on-steel system. Tribol. Int. 2001, 34 (2), 83-88.

36. Jost, H. P., Tribology: The First 25 Years and Beyond-Achievements, Shortcomings and Future Tasks [tribology, as a word and concept, was first enunciated in a British Government Report, published on 9 March 1966(Jost Report)]. Ind. Lubr. Tribol. 1992, 44 (2), 6. 
37. Qiu, S.; Dong, J.; Chen, G., Synthesis of $\mathrm{CeF}_{3}$ nanoparticles from water-in-oil microemulsions. Powder. Technol. 2000, 113 (1-2), 9-13.

38. Hua, R.; Zang, C.; Shao, C.; Xie, D.; Shi, C., Synthesis of barium fluoride nanoparticles from microemulsion. Nanotechnology 2003, 14 (6), 588.

39. Ganguli, A. K.; Ganguly, A.; Vaidya, S., Microemulsion-based synthesis of nanocrystalline materials. Chem. Soc. Rev. 2010, 39 (2), 474-485.

40. Kitchens, C. L.; McLeod, M. C.; Roberts, C. B., Chloride ion effects on synthesis and directed assembly of copper nanoparticles in liquid and compressed alkane microemulsions. Langmuir 2005, 21 (11), 5166-5173.

41. Shi, H.; Qi, L.; Ma, J.; Cheng, H., Polymer-directed synthesis of penniform $\mathrm{BaWO}_{4}$ nanostructures in reverse micelles. J. Am. Chem. Soc. 2003, 125 (12), 3450-3451.

42. Vaucher, S.; Li, M.; Mann, S., Synthesis of Prussian blue nanoparticles and nanocrystal superlattices in reverse microemulsions. Angew. Chem., Int. Ed. 2000, 39 (10), 1793-1796.

43. Lemyre, J.-L.; Ritcey, A. M., Synthesis of lanthanide fluoride nanoparticles of varying shape and size. Chem. Mater. 2005, 17 (11), 3040-3043.

44. Zhang, N.; Xiao, X.; Pang, H., Transition metal (Fe, Co, Ni) fluoride-based materials for electrochemical energy storage. Nanoscale Horiz. 2019, 4 (1), 99-116.

45. Amatucci, G. G.; Pereira, N., Fluoride based electrode materials for advanced energy storage devices. J. Fluorine Chem. 2007, 128 (4), 243-262.

46. Lee, D. H.; Carroll, K. J.; Calvin, S.; Jin, S.; Meng, Y. S., Conversion mechanism of nickel fluoride and NiO-doped nickel fluoride in $\mathrm{Li}$ ion batteries. Electrochim. Acta. 2012, 59, 213-221. 
47. Su, D.; Xie, X.; Dou, S.; Wang, G., CuO single crystal with exposed $\{001\}$ facets-A highly efficient material for gas sensing and Li-ion battery applications. Sci. Rep. 2014, 4, 5753. 48. Billas, I. M.; Becker, J.; Châtelain, A.; de Heer, W. A., Magnetic moments of iron clusters with 25 to 700 atoms and their dependence on temperature. Phys. Rev. Lett. 1993, 71 (24), 4067.

49. Berdonosov, S. S.; Lebedev, V. Y.; Berdonosova, D. G.; Prokofiev, M. A.; Znamenskaya, I. V.; Melikhov, I. V.; Kharisov, B. I.; Méndez, U. O.; Kharissova, O. V., Influence of Microwave Treatment on the Dehydration of Crystallohydrates of Iron, Cobalt and Nickel Flourides. J. Microwave. Power. EE. 2007, 42 (2), 15-20.

50. Boutonnet, M.; Kizling, J.; Stenius, P.; Maire, G., The preparation of monodisperse colloidal metal particles from microemulsions. Colloid. Surface. 1982, 5 (3), 209-225.

51. Moulik, S. P.; Paul, B. K., Structure, dynamics and transport properties of microemulsions. Adv. Colloid Interface Sci. 1998, 78 (2), 99-195.

52. Rossman, G. R.; Shannon, R. D.; Waring, R. K., Origin of the yellow color of complex nickel oxides. J. Solid State Chem. 1981, 39 (3), 277-287.

53. Roth, M.; Hempelmann, R.; Borgmeier, O.; Eifert, T.; Lueken, H., Nanocrystalline $\mathrm{NH}_{4} \mathrm{MnF}_{3}$ with controlled grain size: Synthesis and antiferromagnetism. Nanostruct. Mater. 1999, $12(5-8), 855-858$.

54. Qi, L., Synthesis of inorganic nanostructures in reverse micelles. Encyclopedia of Surface and Colloid Science 2006, 2, 6183-6207.

55. Eastoe, J.; Hollamby, M. J.; Hudson, L., Recent advances in nanoparticle synthesis with reversed micelles. Adv. Colloid Interfac. Sci. 2006, 128, 5-15. 
56. Chandradass, J.; Balasubramanian, M.; Bae, D. S.; Kim, J.; Kim, K. H., Effect of water to surfactant ratio (R) on the particle size of $\mathrm{MgAl}_{2} \mathrm{O}_{4}$ nanoparticle prepared via reverse micelle process. J. Alloy. Compd. 2010, 491 (1-2), L25-L28.

57. Petit, C.; Lixon, P.; Pileni, M. P., In situ synthesis of silver nanocluster in AOT reverse micelles. J. Phys. Chem. 1993, 97 (49), 12974-12983.

58. Patil, K.; Secco, E., Metal halide ammines. II. Thermal analyses, calorimetry and infrared spectra of fluoride ammines and hydrates of bivalent metals. Can. J. Chem. 1972, 50 (4), 567573.

59. Taibi, M.; Ammar, S.; Jouini, N.; Fiévet, F.; Molinié, P.; Drillon, M., Layered nickel hydroxide salts: synthesis, characterization and magnetic behaviour in relation to the basal spacing. J. Mater. Chem. 2002, 12 (11), 3238-3244.

60. Poul, L.; Jouini, N.; Fiévet, F., Layered hydroxide metal acetates (metal= zinc, cobalt, and nickel): elaboration via hydrolysis in polyol medium and comparative study. Chem. Mater. 2000, 12 (10), 3123-3132.

61. Mayo, D. W.; Miller, F. A.; Hannah, R. W., Course notes on the interpretation of infrared and Raman spectra. John Wiley \& Sons: 2004.

62. Jiang, Z.; Xie, J.; Jiang, D.; Wei, X.; Chen, M., Modifiers-assisted formation of nickel nanoparticles and their catalytic application to p-nitrophenol reduction. CrystEngComm 2013, 15 (3), 560-569.

63. Hutchings, M.; Thorpe, M.; Birgeneau, R.; Fleury, P.; Guggenheim, H., Neutron and Optical Investigation of Magnons and Magnon-Magnon Interaction Effects in $\mathrm{NiF}_{2}$. Phys. Rev. B 1970, 2 (5), 1362. 
64. Agulló Rueda, F.; Calleja, J.; Martini, M.; Spinolo, G.; Cariati, F., Raman and infrared spectra of transition metal halide hexahydrates. J. Raman. Spectrosc. 1987, 18 (7), 485-491.

65. Scherer, J. R.; Go, M. K.; Kint, S., Raman spectra and structure of water from-10 to 90. deg. J. Phys. Chem. 1974, 78 (13), 1304-1313.

66. Stout, J.; Reed, S. A., The crystal structure of $\mathrm{MnF}_{2}, \mathrm{FeF}_{2}, \mathrm{CoF}_{2}, \mathrm{NiF}_{2}$ and $\mathrm{ZnF}_{2}$. J. Am. Chem. Soc. 1954, 76 (21), 5279-5281.

67. Klug, H. P.; Alexander, L. E., X-ray diffraction procedures: for polycrystalline and amorphous materials. X-Ray Diffraction Procedures: For Polycrystalline and Amorphous Materials, 2nd Edition, by Harold P. Klug, Leroy E. Alexander, pp. 992. ISBN 0-471-49369-4. Wiley-VCH, May 1974. 1974, 992.

68. Tramšek, M.; Žemva, B., Higher fluorides of nickel: Syntheses and some properties of $\mathrm{Ni}_{2} \mathrm{~F}_{5}$. Acta. Chim. Slov. 2002, 49, 209-220.

69. da Silva Jr, E.; Machado, F.; Rezende, S., High resolution Raman scattering by phonons in $\mathrm{FeF}_{2}$ and $\mathrm{NiF}_{2}$. Solid State Commun. 1983, 48 (12), 1077-1079.

70. Dieguez, A.; Romano-Rodrıguez, A.; Vila, A.; Morante, J., The complete Raman spectrum of nanometric $\mathrm{SnO}_{2}$ particles. J. Appl. Phys. 2001, 90 (3), 1550-1557.

71. Vinayan, B.; Sethupathi, K.; Ramaprabhu, S., Facile synthesis of triangular shaped palladium nanoparticles decorated nitrogen doped graphene and their catalytic study for renewable energy applications. Int. J. Hydrogen. Energ. 2013, 38 (5), 2240-2250.

72. Teng, Y. T.; Wei, F.; Yazami, R., Synthesis of $\mathrm{Ni}_{\mathrm{x}} \mathrm{Co}_{(1-\mathrm{x})} \mathrm{F}_{2}(\mathrm{x}=0,0.25,0.50,0.75,1.0)$ and application in lithium ion batteries. J. Alloy. Compd. 2015, 653, 434-443.

73. Lee, D. H.; Carroll, K. J.; Chapman, K. W.; Borkiewicz, O. J.; Calvin, S.; Fullerton, E.

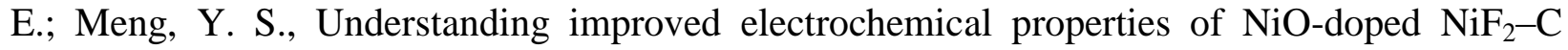


composite conversion materials by X-ray absorption spectroscopy and pair distribution function analysis. Phys. Chem. Chem. Phys. 2014, 16 (7), 3095-3102.

74. Lieser, G.; de Biasi, L.; Scheuermann, M.; Winkler, V.; Eisenhardt, S.; Glatthaar, S.; Indris, S.; Geßwein, H.; Hoffmann, M. J.; Ehrenberg, H., Sol-Gel Processing and Electrochemical Conversion of Inverse Spinel-Type $\mathrm{Li}_{2} \mathrm{NiF}_{4}$. J. Electrochem. Soc. 2015, 162 (4), A679-A686.

75. Cooke, A.; Gehring, K.; Lazenby, R., The magnetic properties of $\mathrm{NiF}_{2}$. P. Phys. Soc. 1965, 85 (5), 967.

76. Brown, P.; Forsyth, J., A neutron diffraction study of weak ferromagnetism in nickel fluoride. J. Phys. C Solid State 1981, 14 (33), 5171.

77. Lang, X.; Wen, Z.; Jiang, Q., Dependence of Thermal Stability of Antiferromagnetic Nanocrystals on Size and Magnetic Proximity Effect. J. Phys. Chem. C 2008, 112 (11), 40554060. 


\section{Table of Contents (TOC)/Abstract Graphic}

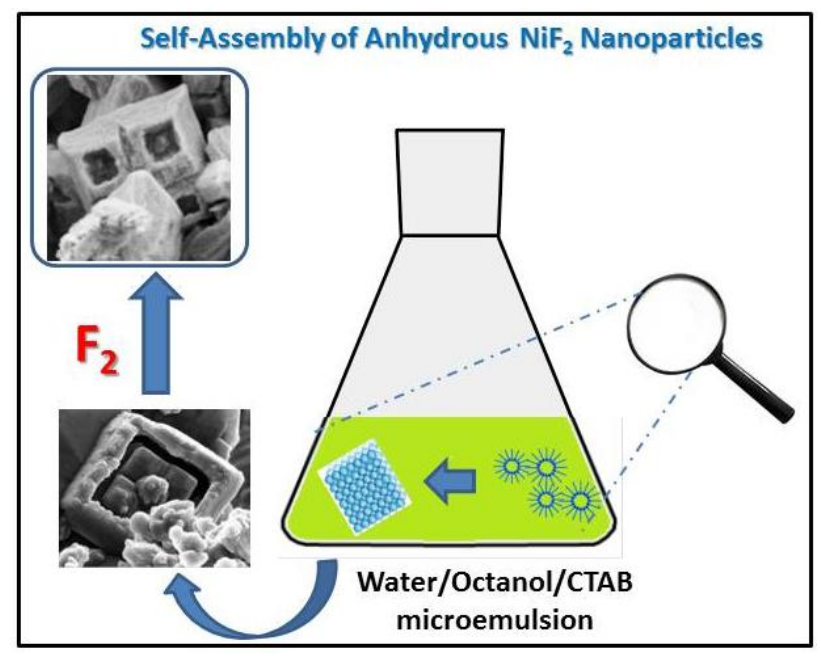

